Article

\title{
Performance Assessment of Japanese Electric Power Industry: DEA Measurement with Future Impreciseness
}

\author{
Toshiyuki Sueyoshi ${ }^{1,2, *}$ and Mika Goto ${ }^{3}$ \\ 1 Department of Management, New Mexico Institute of Mining \& Technology, 801 Leroy Place, Socorro, \\ NM 87801, USA \\ 2 Tokyo Institute of Technology, Tokyo Tech World Research Hub Initiative, School of Environment and \\ Society, 3-3-6 Shibaura, Minato-ku, Tokyo 108-0023, Japan \\ 3 Tokyo Institute of Technology, School of Environment and Society, 3-3-6 Shibaura, Minato-ku, \\ Tokyo 108-0023, Japan; goto.m.af@m.titech.ac.jp \\ * Correspondence: Toshiyuki.Sueyoshi@nmt.edu; Tel.: +1-575-835-6452
}

Received: 25 December 2019; Accepted: 9 January 2020; Published: 19 January 2020

\begin{abstract}
This study examines the performance of Japanese electric power companies from 2003 to 2020. We use an observed data set from 2003 to 2015 and a forecasted data set from 2016 to 2020. The Japanese deregulation of the industry needs to be completed by April 2020. As a method, this study uses data envelopment analysis (DEA) environmental assessment, which measures performance from a holistic perspective. This research adds a new analytical capability to the DEA-based assessment by including an analytical ability to handle an "imprecise" data set. We apply the proposed approach to investigate the performance of these companies before and after the disaster of Fukushima Daiichi nuclear power plant (11 March 2011). All electric power companies have suffered from business damage due to the nuclear disaster. The Japanese government has developed a policy scheme on how to recover from the huge handling costs resulting from the disaster. Nuclear energy has been long considered the most useful approach to handle climate change. However, many industrial nations have changed policy direction since the nuclear disaster. The Japanese government allocates the costs to not only Tokyo Electric Power Company, which produced the nuclear disaster, but also the other incumbent electric power companies that own nuclear power plants. Under the current Japanese scheme, financial conditions have been gradually recovering from the damage due to the managerial efforts and by indirectly allocating the expenditure to consumers and tax payers.
\end{abstract}

Keywords: data envelopment analysis; data impreciseness; Japanese electric power industry

\section{Introduction}

Climate change due to global warming is now a major concern across the world. Climate change refers to an increase in the average global temperature for air, sea and land. Natural events and economic activities, including industrial development and business activities, contribute to an increase in the average global temperature. The change is primarily caused by an increase in greenhouse gases (GHG) such as carbon dioxide $\left(\mathrm{CO}_{2}\right)$. It is necessary for us to combat the environmental problem through international cooperation among industrial and developing nations, green technology innovations, and managerial challenges in public and private sectors [1].

In the global trend, Japan has long been combating various industrial pollution sources including GHG emissions [2]. In reviewing the Japanese environmental policy, we pay attention to a new Basic Energy Plan (BEP) approved by the Japanese Cabinet on 11 April 2014. The BEP discussed a long-term energy policy direction and its industry development. The plan attracted public attention because 
it was the first policy action on a future energy plan after the Great East Japan Earthquake and the disaster at the Fukushima Daiichi nuclear power plant. See Goto and Sueyoshi [3] for a detailed description of the Japanese BEP.

An important implication of the BEP is that it has confirmed the role of nuclear power generation as a base load so that Japan can combat climate change. The BEP also emphasizes that it is necessary for Japan to increase its use of various renewable energy sources (RES) because the disaster has been influential on the Japanese future energy plan, in particular on the nuclear generation.

To compensate for an unavailable capacity of the nuclear power generation, Japanese electric power companies have recently increased the amount of their generations from fossil fuel power plants, in particular from natural gas and oil. The increased usage of these fuels puts pressure on their corporate profits and environmental concerns on $\mathrm{CO}_{2}$ emission. Even under such unforeseeable future situations, Japanese electric power companies currently operate under a pressure of the market reform prepared by the government, while they need to maintain their stable electricity supplies (e.g., Goto et al. [4], Goto and Sueyoshi, [3,5] and Goto and Takahashi [6]).

Such changes in the industry may be observed in the performance of Tokyo Electric Power Company (TEPCO). For example, the total amount of electricity sold was $280.2 \mathrm{TWh}$ (Terawatt hour) in 2009 and was 247.1 TWh in 2015. The generation amount from fossil fuel power plants was 161.2 TWh in 2009 and was 198.2 TWh in 2015, so increasing 37 TWh during the 6 years. Meanwhile, the total nuclear power generation was 80.9 TWh in 2009, while it became zero in 2015 . Thus, the company had to stop the nuclear generation after the disaster and the generation amount was compensated by fossil fuels and other types of generation (e.g., renewable and water) [7]. As a result, the amount of $\mathrm{CO}_{2}$ emission increased from 1075 in 2009 to 1236 (unit: 100,000 ton- $\mathrm{CO}_{2}$ ) in 2015. See [8].

A difficulty of their operations as corporate entities is summarized as an inquiry: How can the electric power firms maintain a balance between economic prosperity and environmental protection under governmental regulation on their operations? To handle the difficulty, this research proposes a new use of DEA-based assessment that can be applied to the three types of production factors such as desirable outputs, undesirable outputs and inputs in their operational components. Here, DEA stands for "Data Envelopment Analysis".

The purpose of this study is to document how the proposed DEA approach can measure the performance of Japanese electric power companies from 2003 to 2020. Methodologically speaking, a unique feature of the data set to be examined is that it consists of an observed one from 2003 to 2015 and a forecasted (imprecise) one from 2016 to 2020. The annual periods are important in planning the future of Japanese electric power industry because all companies have suffered from business damage due to the nuclear disaster. The Japanese government has developed a policy scheme on how to recover from a huge amount of handling costs due to the disaster. It is important for this study to examine their business changes and future directions.

The remainder of this research is organized as follows. Section 2 summarizes previous research efforts related to this study. Section 3 describes the current business surroundings of the Japanese electric power industry. Section 4 describes an approach to measure unified (operational and environmental) efficiency. Section 5 applies the proposed method to the Japanese electric power industry. Section 6 concludes this study and highlights future extensions. Abbreviations and variables are listed at the end of this article.

\section{Literature Summary}

This section consists of the three groups of previous studies. They are related to the (a) Japanese electric power industry, (b) DEA applied to energy and climate change and (c) data impreciseness for forecasting. These studies serve as conceptual and methodological foundations for the preparation of this research. 


\subsection{Previous Studies on Japanese Electric Power Industry}

The Japanese electric power industry has been adopting government deregulation policy since 1995. In 1995, partial competition was introduced in a generation sector in the first electricity system reform. Then, retail competition was gradually introduced and eligibility was expanded under the second (1999) and third (2003) reforms. Before the changes, ten vertically-integrated, investor-owned electric power companies, such as TEPCO, had supplied electricity to consumers in their regionally monopolized business areas.

The deregulation process influenced research on the Japanese electric power industry. Before the 1995 deregulation, there was no competition in the business of Japan's electric power companies. Almost no research was interested in studies on electric power companies, in particular on their productivity, efficiency and competitiveness measures. After deregulation, many studies started publishing their research efforts on productivity and efficiency analysis, industrial structure changes, and impacts of market liberalization. Those works included Goto and Sueyoshi [5,9], Li et al. [10], Sueyoshi and Goto [11-13], Goto et al. [4], Goto and Takahashi [6], Hosoe and Tanaka [14], and Wang and Mogi [15].

Most of the previous studies applied an econometric analysis to a data set that consisted of Japanese incumbent electric power companies. On the other hand, some studies, including Sueyoshi and Goto [11-13], used DEA for their analyses. However, their DEA applications have not paid attention to how to treat data impreciseness for future assessment. No research has considered the implication of the data imprecision on the future performance of the Japanese electric power industry. This study is the first to explore the research issue.

\subsection{Previous Studies on DEA Applied to Energy and Climate Change}

It is known that DEA has been used in previous research efforts on performance assessment. However, their applications have not incorporated the proposed research scope because they need to consider the existence of undesirable outputs (e.g., $\mathrm{CO}_{2}$ emissions) for environmental assessment.

For example, the data structure between $X$ (inputs) and $G$ (desirable outputs) was discussed in previous DEA research. However, it does not fit its environmental assessment because we need to incorporate $B$ (undesirable outputs) as the by-products of $G$. Thus, the output unification between $G$ and $B$ needs to be considered in this research.

Previous works on DEA contain many research efforts applied to energy and environment. For example, as discussed in Sueyoshi et al. [16], almost 700 peer-reviewed articles have been published in the past four decades. Sueyoshi and Goto [2] provided information on more than 800 articles on DEA that included applications to energy and environment. Since the two literature surveys discussed most of the previous woks on DEA environmental assessment, this research does not describe all of them, except for noting that the number of publications has drastically increased, particularly since 2010.

To describe DEA's popularity applied to energy areas, Table 1 summarizes the previous publications [17-34]. Most of the works were interested in energy efficiency (EE) enhancement by using DEA-based applications. The previous studies with environment ENV investigated the performance assessment on environment protection efforts. Acknowledging their contributions, it is necessary to describe that a methodological difficulty still exists in the assessments because they do not discuss how to handle data impreciseness for future planning and its related performance evaluation. 
Table 1. Recent Studies on DEA Applied to Energy and Environment.

\begin{tabular}{|c|c|c|}
\hline Reference & Summary & Topic \\
\hline [17] & $\begin{array}{l}\text { Within a conventional DEA model, the study used the concept of weak and strong disposability to } \\
\text { measure Chinese coal-fired power plants. }\end{array}$ & ENV \\
\hline [18] & $\begin{array}{l}\text { Proposed a method to evaluate energy efficiency performance of OECD and non-OECD countries } \\
\text { from } 2005 \text { to } 2012 \text {. Took into account the joint inputs and sub-joint inputs to reveal the specific } \\
\text { information on how inputs were allocated to outputs. }\end{array}$ & $\mathrm{EE}$ \\
\hline [19] & $\begin{array}{l}\text { Discussed DEA window analysis approach and Moran's Index were used to analyze the industrial } \\
\mathrm{CO}_{2} \text { emission efficiency and reduction potential. }\end{array}$ & ENV \\
\hline [20] & $\begin{array}{l}\text { Constructed a slacks-based measure DEA model and an index of total-factor energy efficiency to } \\
\text { investigate the energy efficiency of the } 29 \text { provincial-administrative regions in China during } \\
\text { 1997-2011. }\end{array}$ & $\mathrm{EE}$ \\
\hline [21] & $\begin{array}{l}\text { Proposed a DEA-based approach to allocate China's national } \mathrm{CO}_{2} \text { emissions and energy intensity } \\
\text { reduction targets over Chinese provincial industrial sectors. }\end{array}$ & EE, ENV \\
\hline [22] & Discussed a potential of available technologies to prevent the climate change in the United States. & $\mathrm{EE}$ \\
\hline [23] & $\begin{array}{l}\text { Adopted DEA to evaluate the energy efficiency in China's coastal areas over the period of } \\
\text { 2000-2012. Carbon dioxide, sulfur dioxide and nitrogen oxide were treated as undesirable outputs } \\
\text { of energy consumptions. }\end{array}$ & $\mathrm{EE}$ \\
\hline [24] & $\begin{array}{l}\text { A DEA model was developed for assessing performance of PV installations and applied to a large } \\
\text { set of rooftop PV installations in California from } 2008 \text { to } 2012 \text {. }\end{array}$ & ENV \\
\hline [25] & $\begin{array}{l}\text { Two total factor productivities (TFP), namely energy adjusted TFP and energy and carbon dioxide } \\
\text { emissions adjusted TFP, were estimated using superefficiency DEA models for } 30 \text { Chinese provinces } \\
\text { over the period 1997-2010. }\end{array}$ & EE, ENV \\
\hline [26] & $\begin{array}{l}\text { Proposed a tractable method for obtaining systemic Pareto optimal allocation schemes using DEA } \\
\text { and three allocation of emission permits models were developed with taking account of different } \\
\text { real-world scenarios. }\end{array}$ & ENV \\
\hline [27] & $\begin{array}{l}\text { Proposed network range adjusted environmental DEA and examined the impacts of carbon neutral } \\
\text { growth from } 2020 \text { strategy on airline environmental inefficiency. }\end{array}$ & ENV \\
\hline [28] & Proposed a decomposition approach to measure components of $\mathrm{CO}_{2}$ emission in Chinese provinces. & ENV \\
\hline [29] & $\begin{array}{l}\text { Measured unified efficiency of fossil fuel power plants across provinces in China by non-radial } \\
\text { directional distance functions. }\end{array}$ & $\mathrm{EE}$ \\
\hline [30] & $\begin{array}{l}\text { Measured unified efficiency of Chinese fossil fuel power plants by intermediate approach and } \\
\text { window analysis. }\end{array}$ & ENV \\
\hline [31] & $\begin{array}{l}\text { The non-radial directional distance function and the global data envelopment analysis method were } \\
\text { combined to measure the unified (technical, allocative, operational and environmental) efficiency of } \\
\text { Chinese service sector. }\end{array}$ & ENV \\
\hline [32] & $\begin{array}{l}\text { Three methodological difficulties in DEA approach was examined in applying DEA to corporate } \\
\text { sustainability assessment of Japanese industries: how to handle zero and/or negative values, how to } \\
\text { unify inputs, desirable, and undesirable outputs within a synchronized framework, and how to } \\
\text { identify a possible occurrence of a production limit and green technology innovation. }\end{array}$ & ENV \\
\hline [33] & $\begin{array}{l}\text { Assessed road transportation sustainability by combining environmental impacts and } \\
\text { environmental concerns. }\end{array}$ & ENV \\
\hline [34] & $\begin{array}{l}\text { Proposed a modified DEA approach that recognized the two objectives of income maximization and } \\
\text { pollution abatement cost minimization considering regional collaboration. The approach was } \\
\text { applied to measure industrial carbon allocation in China. }\end{array}$ & ENV \\
\hline
\end{tabular}

The abbreviations are as follows: DEA: data envelopment analysis, TEP: total factor productivities, OECD: organization for economic co-operation and development, $\mathrm{CO}_{2}$ : carbon dioxide, EE: energy efficiency and ENV: environment.

\subsection{Previous Studies on Data Impreciseness}

Two groups of previous studies have explored the imprecise data within the conventional DEA framework. Here, "conventional" means that DEA models did not incorporate $B$. In the first group, the production factors used in those previous studies are $X$ and G. See, for example, Cooper et al. [35], who applied chance-constraint analysis to handle an imprecise DEA model that incorporated a concept of "risk" related to future uncertainty. Sueyoshi [36] also applied the same analysis to predict the future performance of Japanese petroleum industry; see Chen [37] and Cooper et al. [38] as well. An important feature of the group is that all studies have considered data impreciseness as a stochastic process and transferred it into a linear programming equivalent. However, they did not incorporate $B$ into their computational frameworks so that these direct applications would suffer from double standards on satisficing $G$ (maximization) and $B$ (minimization). Acknowledging the importance of considering $B$, 
this study does not incorporate the stochastic approach as found in these previous works. Rather, we will use a new approach (i.e., the range of a supporting hyperplane) to express data impreciseness to avoid the double standard issue.

The second group assumed an error distribution to express the stochastic uncertainty in production factors. For example, research on DEA under uncertainty, such as Kao and Liu [39], used a fuzzy function to express uncertainty. Liu [40] discussed how to use DEA-based fuzzy assessment on flexible manufacturing systems to improve their technology, competitiveness and profitability by enhancing manufacturing effectiveness. Liu [41] further extended the fuzzy-based DEA approach by assurance region analysis (ARA), which provided constraints on multipliers, or dual variables; see Thompson et al. [42] on ARA. The proposed DEA approach by Liu [40,41] was promising; however, this study cannot utilize the proposed approach because we need to incorporate $B$ a requirement of this study.

Position (originality) of this study: Acknowledging the importance of previous efforts on data impreciseness (e.g., corporate performance from 2016 to 2020 in this study) in energy and climate change, this research makes four contributions to the literatures. First, this study differs from the prior studies by incorporating an analytical capability to handle the data impreciseness into DEA environmental assessment. The capability is important because energy policy is for future planning with data impreciseness. Second, a unique feature of the proposed approach is that it incorporates the upper and lower bounds on a supporting hyperplane in order to handle the data impreciseness. See Liu $[40,41]$ that had a similar research spirit (i.e., a use of ARA), but not considering both the existence of $B$ and the supporting hyperplane. Third, the proposed approach needs to consider environmental assessment which needs to integrate $G$ and $B$ in a unified structure, including $X$. Finally, this type of approach has been never applied to the performance assessment of Japanese electric power industry.

\section{Current Business Surroundings of Japanese Electric Power Industry}

As described in Section 2, the Japanese electric power industry has been conducting gradual market liberalization since 1995. Although the Ministry of Economy, Trade and Industry (METI) tried to facilitate institutional reforms in an efficient manner, the change still belonged to part of the global trend of electricity market liberalization. METI issued cautions to the electric power industry on reform advancement because the progress was slower than that of other industrial nations. However, the situation drastically changed after the Great East Japan Earthquake in March 2011 and the Fukushima Daiichi nuclear power accident. In the aftermath of the disaster, a system reform of the electricity market gained momentum and started the three-step reform plan.

The first step was to establish the Organization for Cross-regional Coordination of Transmission Operators (OCCTO) in April 2015, whose missions promoted the development of electricity transmission and distribution networks which were necessary for cross-regional electricity uses. OCCTO also attempted to enhance the nationwide function of maintaining the supply-demand balance of electricity in both normal and emergency situations.

The second step was to implement full liberalization of the retail market in April 2016, which gave regulated consumers (mainly residential users) eligibility to choose an electricity supplier among incumbent and new entrant companies. In addition, licensing unbundling was introduced in April 2016, under which the electricity supply was composed of three sectors with different licenses: generation, transmission and distribution and retail. Now, anyone can enter the generation sector by notifying METI, and retail sector entrants need to register when starting their business activities. The transmission and distribution sector has remained in regional monopoly and is still constrained by the license and regulation on the business.

The final step will be planned in April of 2020 to implement legal unbundling of the transmission/distribution sector from the generation and retail sectors. The purposes of the separation are to secure a high level of fairness for all players in the electricity generation and retail markets, and to facilitate competition among them, because incumbent companies own all three licenses, particularly a transmission and distribution license. 
Until now, only TEPCO has already separated the transmission and distribution business from the other sectors. It has established a holding company, TEPCO Holdings. The company has the three separated sub-companies, including fuel and fossil fuel power generation (TEPCO Fuel and Power Inc.), transmission and distribution (TEPCO Power Grid Inc.), and retail businesses (TEPCO Energy Partner Inc.). Currently, TEPCO and the other electric power companies face many business challenges associated with costs incurred by the Fukushima's nuclear disaster. They have also conducted operational reforms for adapting to new technology and innovations such as energy digitalization, de-carbonization, and distributed energy.

\section{Method}

\subsection{Natural Disposability}

This research incorporates the concept of "natural disposability", which implies the elimination of inefficiency within the framework of performance assessment (first priority: economic prosperity; second priority: environmental protection) [2]. In the concept, an inefficient decision making unit (DMU, e.g., an electric power company to be evaluated in this study) decreases some components of $X$ or maintains them at their current levels, but increases some components of $G$. It can be assumed that the decrease of $X$ naturally reduces $B$.

It is well known that the natural disposability is usually associated with an opposite concept, referred to as "managerial disposability" in which the first priority is environment protection and the second one is economic prosperity. The disposability requests that each DMU needs to increases $X$ for the increase of $G$ and the decrease of $B$. This research utilizes only the natural disposability, not the managerial disposability, because Japanese electric power companies need to pay attention to their operational efficiencies (so, natural disposability) under the current liberalization process of the Japanese government. See Section 3 and [2]. It is expected that they will gradually shift from the natural disposability to the managerial one.

Under natural disposability, this research incorporates a possible occurrence of congestion (UC: undesirable congestion). The occurrence directly implies a capacity limit on transmission in a grid system. An economic stagnation is another example of this type of congestion. The second example may fit within the scope of this research.

\subsection{Data Impreciseness}

The data set of Japanese electric power companies from 2003 to 2020 is separated into an observed data set from 2003 to 2015 and a forecasted (imprecise) one from 2016 to 2020. It is straightforward to apply our previous DEA approach, discussed in [2], to the first data set (2003-2015). However, we need to restructure the previous formulation to handle the second data set (2016-2020) because it contains data impreciseness.

To discuss how to handle the second data set, let us consider a DMU ( $j)$ which has a data structure with impreciseness. Using the three production factors ( $x$ : input, $g$ : desirable output and $b$ : undesirable output) of the specific $j$ th DMU $(j=1, \ldots, n)$ to be evaluated, the data ranges become

$$
\tilde{x}_{i j}=\left[x_{i j}^{L}, x_{i j}^{U}\right] \text { for all } i, \widetilde{g}_{r j}=\left[g_{r j}^{L}, g_{r j}^{U}\right] \text { for all rand } \tilde{b}_{f j}=\left[b_{f j}^{L}, b_{f j}^{U}\right] \text { for all } f \text {. }
$$

where $\sim$ expresses the data impreciseness that is specified by the upper and lower bounds. The two superscripts ( $\mathrm{L}$ and $\mathrm{U}$ ) stand for the two bounds of each production factor. 
Next, this research uses another type of data range on each factor:

$$
\begin{aligned}
& R_{i}^{x}=(m+s+h)^{-1}\left(\max _{j}\left\{x_{i j} \mid j=1, \ldots, n\right\}-\min _{j}\left\{x_{i j} \mid j=1, \ldots, n\right\}\right)^{-1}, \\
& R_{r}^{g}=(m+s+h)^{-1}\left(\max _{j}\left\{g_{r j} \mid j=1, \ldots, n\right\}-\min _{j}\left\{g_{r j} \mid j=1, \ldots, n\right\}\right)^{-1} \& \\
& R_{f}^{b}=(m+s+h)^{-1}\left(\max _{j}\left\{b_{f j} \mid n=1, \ldots, n\right\}-\min _{j}\left\{b_{f j} \mid n=1, \ldots, n\right\}\right)^{-1} .
\end{aligned}
$$

It is important to note that the data ranges (1) are applicable to both deterministic and imprecise cases because we measure just the upper and lower numbers of each factor so that we always have $R_{i}^{x}=\widetilde{R}_{i}^{x}, R_{r}^{g}=\widetilde{R}_{r}^{g}, R_{f}^{b}=\widetilde{R}_{f}^{b}$ in these data ranges, where the ranges on the left hand side are deterministic and those of the right hand side are imprecise. Therefore, this research does not need to use the symbol $(\sim)$ on the three ranges, hereafter.

\subsection{Supporting Hyperplane}

To handle data impreciseness, we consider a possible range on a supporting hyperplane so that we can shift the data impreciseness to a corresponding deterministic formulation. As a result of the reformulation, we can solve DEA with data impreciseness by linear programming. Mathematically, the supporting hyperplane is determined by dual variables of linear programming formulation. This subsection is aimed to provide a visual description on how to deal with the data impreciseness.

Figure 1 depicts the upper and lower bounds of a possible supporting hyperplane with an imprecise data set. For visual convenience, the figure considers only a single input, $\widetilde{x}=\left[x^{L}, x^{U}\right]$, and a single desirable output, $\widetilde{g}=\left[g^{L}, g^{U}\right]$. An undesirable output, $\widetilde{b}=\left[b^{L}, b^{U}\right]$, is not listed in Figure 1. A supporting hyperplane, passing on DMU $\{\mathrm{A}\}$, locates an efficiency frontier in the data domain of $x$ and $g$. The supporting hyperplane becomes a line because there is no coordinate on $b$.

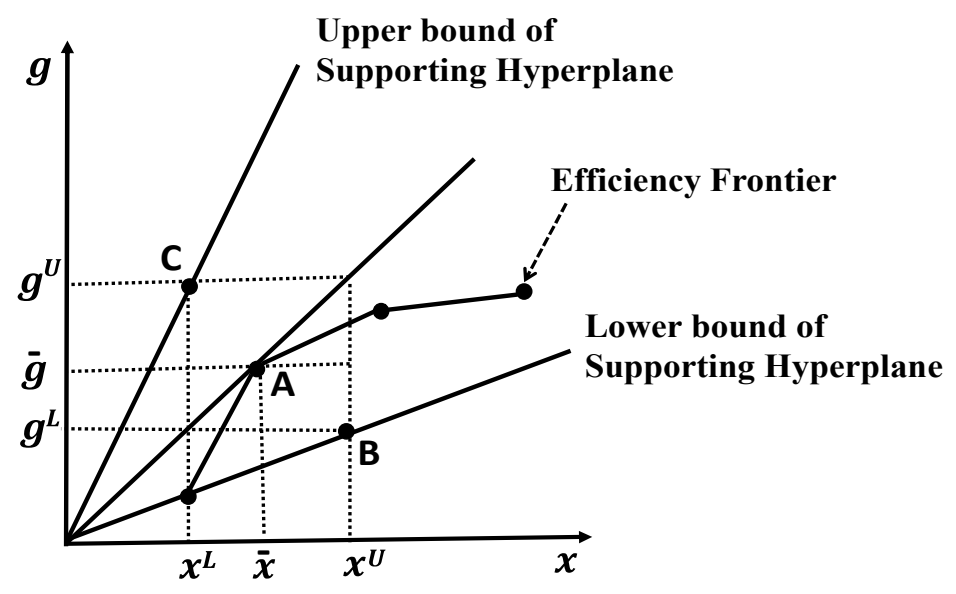

Figure 1. Range for supporting line on $x$ and $g$.

Here, let us assume that the supporting hyperplane is expressed by $v \widetilde{x}-u \widetilde{g}+w \widetilde{b}+\sigma=0$, where $v, u, w$, and $\sigma$ are unknown parameters to be estimated. The imprecise data ranges specify the ratios among the three production components by $g^{L} / x^{U} \leq v / u \leq g^{U} / x^{L}$. In Figure $1,\{\mathrm{~B}\}$ indicates the slope of $g^{L} / x^{U}$ as a lower bound of the hyperplane and $\{C\}$ indicates the slope of $g^{U} / x^{L}$ as its upper bound. Thus, the data impreciseness is expressed by the upper and lower bounds of the slope.

(a) A supporting hyperplane passes on $\operatorname{DMU}\{\mathrm{A}\}$. The location of $x$ and $g$ determine the supporting hyperplane (line). Since the figure does not have a coordinate for $b$ (assuming that all DMUs are the same), the hyperplane becomes a supporting line. 
(b) The $\{\mathrm{A}\}$ locates on $\bar{x}$ in the horizontal axis and $\bar{g}$ in the vertical axis. Both locate between $\mathrm{L}$ (a lower bound) and $U$ (an upper bound).

(c) The location of $\{B\}$ indicates the slope of $g^{L} / x^{U}$ as a lower bound. Meanwhile, the location of $\{C\}$ indicates the slope of $g^{U} / x^{L}$ as an upper bound.

(d) The data impreciseness is expressed by the upper and lower bounds of the slope of the supporting hyperplane.

As depicted in Figure 1, the impreciseness of data components is replaced by the upper and lower bounds of the slope of a supporting hyperplane. Of course, the proposed approach might not be optimal, but it is a promising approach by which to handle data impreciseness without any assumptions. Furthermore, the proposed approach may enhance computational feasibility because we can solve the problem of data impreciseness by linear programing.

\subsection{Original Formulations}

This section describes mathematical formulations to measure the degree of unified (operational and environmental) efficiency (UE).

The proposed assessment considers that there are $n$ DMUs. The $j$ th DMU $(j=1, \ldots, n)$ uses $\widetilde{X}_{j}=\left(\widetilde{x}_{1 j}, \widetilde{x}_{2 j}, \ldots, \widetilde{x}_{m j}\right)^{T}$ to produce both $\widetilde{G}_{j}=\left(\widetilde{g}_{1 j}, \widetilde{g}_{2 j}, \ldots, \widetilde{g}_{s j}\right)^{T}$ and $\widetilde{B}_{j}=\left(\widetilde{b}_{1 j}, \widetilde{b}_{2 j}, \ldots, \widetilde{b}_{h j}\right)^{T}$. The superscript $(T)$ indicates a vector transpose. These column vectors are referred to as "production factors" in this study. It is assumed that all components of the three vectors are strictly positive.

This research used the following model to measure the unified efficiency of the $k$ th DMU under a possible occurrence of undesirable congestion (UC):

$$
\begin{array}{lll}
\text { Maximize } & \xi+\varepsilon_{s}\left(\sum_{i=1}^{m} R_{i}^{x} d_{i}^{x-}+\sum_{r=1}^{s} R_{r}^{g} d_{r}^{g}\right) & \\
\text { s.t. } & \sum_{j=1}^{n} \widetilde{x}_{i j} \lambda_{j}+d_{i}^{x-}=\widetilde{x}_{i k} & (i=1, \ldots, m), \\
& \sum_{j=1}^{n} \widetilde{g}_{r j} \lambda_{j}-d_{r}^{g}-\widetilde{g}_{r k}=g_{r k} & (r=1, \ldots, s), \\
& \sum_{j=1}^{n} \widetilde{b}_{f j} \lambda_{j}+\widetilde{\xi}_{f k}=b_{f k} & (f=1, \ldots, h), \\
& \sum_{j=1}^{n} \lambda_{j}=1, & \\
& \lambda_{j} \geq 0(j=1, \ldots, n), \xi: U R S, & \\
& d_{i}^{x-} \geq 0(i=1, \ldots, m) \& d_{r}^{s} \geq 0 \quad(r=1, \ldots, s) .
\end{array}
$$

where " $k$ " indicates the specific $k$ th DMU to be evaluated. The subscript $(j)$ indicates the $j$ th DMU for $j$ $=1, \ldots, n$. The left hand side $\left(\sum_{j=1}^{n} x_{i j} \lambda_{j}, \sum_{j=1}^{n} g_{r j} \lambda_{j}, \sum_{j=1}^{n} b_{f j} \lambda_{j}\right)$ indicates an efficiency frontier and implies a composite (or ideal) performance of the $k$ th DMU.

Model (1) has seven unique features. First, $\lambda=\left(\lambda_{1}, \ldots, \lambda_{n}\right)^{T}$ is often referred to as comprising "structural" or "intensity" variables. They are used for connecting $X, G$ and $B$ by a convex combination. Second, since Model (1) includes the constraint for the sum of structural variables, the production and pollution possibility set in Model (1) is formulated under variable returns to scale (RTS). Third, Model (1) considers only single-sided input deviations $\left(d_{i}^{x-}=x_{i k}-\sum_{j=1}^{n} x_{i j} \lambda_{j} \geq 0\right)$ for $X$ in order to attain the status of natural disposability. Fourth, a scalar value $(\xi)$ stands for an inefficiency score that measures the distance between two efficiency frontiers and an observed vector on $G$ and $B$. Fifth, the symbol (URS) means "unrestricted." A scalar value $\varepsilon_{s}$ represents a very small number that indicates the relative importance between the inefficiency measure and the total sum of slacks. The small number should be prescribed by a user in the manner that the efficiency score locates between zero (full inefficiency) and one (full efficiency). This study sets $\varepsilon_{s}=0.0001$. Sixth, this type of measurement belongs to the Debreu-Farrell criterion used in the radial models [2]. Finally, the equations, or 
$\sum_{j=1}^{n} b_{f j} \lambda_{j}+\xi b_{f k}=b_{f k}(f=1, \ldots, h)$, drop slacks associated with $B$ in order to incorporate a possible occurrence of UC.

The unified efficiency under natural disposability $(U E N)$ of the $k$ th DMU with a possible UC occurrence is measured by

$$
U E N_{k}^{*}=1-\left[\xi^{*}+\varepsilon_{s}\left(\sum_{i=1}^{m} R_{i}^{x} d_{i}^{x-*}+\sum_{r=1}^{s} R_{r}^{g} d_{r}^{g *}\right)\right]
$$

where the inefficiency score and all slack variables are determined on the optimality of Model (1). The superscript $(*)$ indicates optimality. The equation within the parentheses indicates the level of unified inefficiency. The UEN is obtained by subtracting the level of inefficiency from unity, as specified in Equation (2).

To mathematically discuss the importance of the upper and lower bounds of a supporting hyperplane in absorbing data impreciseness, this study needs to prepare the following dual formulation of Model (2):

$$
\begin{aligned}
& \text { Maximize } \quad \sum_{i=1}^{m} v_{i} x_{i k}-\sum_{r=1}^{s} u_{r} g_{r k}+\sum_{f=1}^{h} w_{f} b_{f k}+\sigma \\
& \text { s.t. } \quad \sum_{i=1}^{m} v_{i} \widetilde{x}_{i j}-\sum_{r=1}^{s} u_{r} \widetilde{g}_{r j}+\sum_{f=1}^{h} w_{f} \widetilde{b}_{f j}+\sigma \geq 0 \quad(j=1, \ldots, n) \text {, } \\
& \sum_{r=1}^{s} u_{r} \widetilde{g}_{r k}+\sum_{f=1}^{h} w_{f} \widetilde{b}_{f k}=1 \\
& v_{i} \geq \varepsilon_{S} R_{i}^{x} \\
& u_{r} \geq \varepsilon_{s} R_{r}^{g} \\
& w_{f}: \text { URS } \\
& \sigma: \text { URS. }
\end{aligned}
$$

where $v_{i}(i=1, \ldots, m), u_{r}(r=1, \ldots, s), w_{f}(f=1, \ldots, h)$, and $\sigma$ are all dual variables related to the first, second, third, and fourth groups of constraints in Model (2), respectively. Each dual variable indicates the level of an increase in unified inefficiency due to a unit increase in each production factor. Paying attention to $w_{f}$ : URS $(f=1, \ldots, h)$ in Model (4), we can identify that the slope of a supporting hyperplane is determined by the sign of $w_{f}(f=1, \ldots, h)$.

The degree of $U E N$ of the $k$ th DMU is measured by the following equation:

$$
\operatorname{UEN}_{k}^{*}=1-\left(\sum_{i=1}^{m} v_{i}^{*} \widetilde{x}_{i k}-\sum_{r=1}^{s} u_{r}^{*} \widetilde{r}_{r k}+\sum_{f=1}^{h} w_{f}^{*} \widetilde{b}_{f k}+\sigma^{*}\right),
$$

because the objective value of Model (2) equals that of Model (4) on optimality.

\subsection{Handling Data Impreciseness}

A major problem of formulations from (2) to (4) is that they include stochastic variables ( ) due to the data impreciseness. As a result, we cannot solve them by linear programming. As depicted in Figure 1, we need to change the impreciseness into the upper and lower bounds of the slop of a supporting hyperplane. For the purpose, this study incorporates multiplier restriction into Model (3) in such a manner that these estimates represent the range of a supporting hyperplane.

To simplify our discussion hereafter, we consider the supporting hyperplane in a simple case (i.e., a single component of each factor). The hyperplane becomes $v \widetilde{x}-u \widetilde{g}+w \vec{b}+\sigma=0$, as discussed in Sueyoshi and Goto [1]. The ratios between factors become $\partial \widetilde{g} / \partial \widetilde{x}=v / u$ and $\partial \widetilde{g} / \partial \widetilde{b}=w / u$. Since they have the lower and upper bounds, these factor ratios are expressed by the two conditions $g^{L} / x^{U} \leq v / u \leq g^{U} / x^{L}$ and $g^{L} / b^{U} \leq w / u \leq g^{U} / b^{L}$. 
The extension to the case of multiple components of $X, G$ and $B$ indicates the following equations:

$$
\begin{gathered}
g_{r}^{L} / x_{i}^{U} \leq v_{i} / u_{r} \leq g_{r}^{U} / x_{i}^{L}(i=1, \ldots, m \& r=1, \ldots, s) \text { and } \\
g_{r}^{L} / b_{f}^{U} \leq w_{f} / u_{r} \leq g_{r}^{U} / b_{f}^{L}(r=1, \ldots, s \& f=1, \ldots, h)
\end{gathered}
$$

After incorporating Equations (6), Model (4) becomes

$$
\begin{array}{ccc}
\text { Maximize } & \sum_{i=1}^{m} v_{i} \bar{x}_{i k}-\sum_{r=1}^{s} u_{r} \bar{g}_{r k}+\sum_{f=1}^{h} w_{f} \bar{b}_{f k}+\sigma \\
\text { s.t. } & \sum_{i=1}^{m} v_{i} \bar{x}_{i j}-\sum_{r=1}^{s} u_{r} \bar{g}_{r j}+\sum_{f=1}^{h} w_{f} \bar{b}_{f j}+\sigma \geq 0 & (j=1, \ldots, n), \\
0 \leq \quad \sum_{i=1}^{m} v_{i} \bar{x}_{i k}-\sum_{r=1}^{s} u_{r} \bar{g}_{r k}+\sum_{f=1}^{h} w_{f} \bar{b}_{f k}+\sigma \leq 1, & \\
\sum_{r=1}^{s} u_{r} \bar{g}_{r k}+\sum_{f=1}^{h} w_{f} \bar{b}_{f k}=1, & \\
\text { the same equations }(6), & (i=1, \ldots, m), \\
v_{i} \geq \varepsilon_{s} R_{i}^{x} & (r=1, \ldots, s), \\
u_{r} \geq \varepsilon_{s} R_{r}^{g} & (f=1, \ldots, h) \& \\
w_{f}: \text { URS } & \sigma: \text { URS. }
\end{array}
$$

In Model (7), estimated values $\left(\bar{x}_{i j}, \bar{y}_{r j}, \bar{b}_{f j}\right)$ are used as the three production factors. For example, their forecasted average values are used in Model (7). See Figure 1.

The level of UEN on the $k$ th DMU is measured by

$$
U E N_{k}^{*}=1-\left(\sum_{i=1}^{m} v_{i}^{*} \bar{x}_{i k}-\sum_{r=1}^{s} u_{r}^{*} \bar{g}_{r k}+\sum_{f=1}^{h} w_{f}^{*} \bar{b}_{f k}+\sigma^{*}\right),
$$

where all dual variables are determined by the optimality of Model (7).

It is important to note two concerns regarding Model (7). One of them is that the data impreciseness on $X, G$ and $B$ is replaced by the upper and lower bounds on multiplier ratios as formulated by Model (7). Such a reformulation indicates a new formulation for DEA-based assessment. The other concern is that we incorporate the additional constraint $\left(0 \leq \sum_{i=1}^{m} v_{i} \bar{x}_{i k}-\sum_{r=1}^{s} u_{r} \bar{g}_{r k}+\sum_{f=1}^{h} w_{f} \bar{b}_{f k}+\sigma \leq 1\right)$ in Model (7) to maintain the efficiency requirement (0: Full inefficiency and 1: Full efficiency).

\subsection{Forecasting}

This study extends the proposed analytical capability for handling the data impreciseness for forecasting. The extension is important because the forecasted data usually contain the impreciseness. After applying a forecasting method, the performance of the $j$ th DMU in the specific $t$ th period contains the predicted three production factors $\left(\bar{x}_{i j t}\right.$ for all $i, \bar{g}_{r j t}$ for all $r$, and $\bar{b}_{f j t}$ for all $f$ ). Here, the above symbol indicates a forecasted value on each factor. Given the forecasted values (e.g., an average between forecasted upper and lower bounds) on the three factors (i.e., 2016-2020 in this study), we reorganized Model (7) by incorporating the $t$ th period to express a time horizon $(t=2016-2020)$.

\section{Empirical Study of Japanese Electric Power Companies}

\subsection{Assessment Process}

This research is interested in examining the performance of Japanese electric power companies from 2003 to 2020 using an observed data set from 2003 to 2015 and a forecasted data set from 2016 to 2020. To attain the research objective, we used three data sets: (a) The observed data set from 2003 to 
2015 for DEA assessment, (b) 2015 data for a methodological comparison, and (c) the forecasted data for 2016 and 2020. The forecasted data need to handle the data impreciseness.

The three tasks have the following different research purposes: The first case (2003-2015) examines the influence of OCCTO by measuring the operations of Japanese electric power companies until April 2015. They had to develop their electricity transmission and distribution networks which were necessary for cross-regional electricity uses. The OCCTO attempted to enhance the nationwide function of maintaining the supply-demand balance of electricity in both normal and emergency situations. The second case (2015 data) examines the methodological validity of the proposed approach that newly incorporates an analytical capability to handle the data impreciseness. The last case (2016-2020) examines the influence of full liberalization of the retail market implemented in April 2016 which has provided regulated consumers (mainly residential users) with the eligibility to choose an electricity supplier among incumbent and new entrant companies. The plan will be completed in April of 2020 by implementing legal unbundling of the transmission/distribution sector from generation and retail sectors.

Figure 2 explains how we apply the proposed approach for the assessment of the Japanese electric power industry. First, this study classifies an observed data set (2003-2015) into two sets, one of which is used as a validation sample (only 2015). The other (2003-2014) is used as an observed data set. We use the validation sample (2015) for the methodical comparison between Model (2) without data impreciseness and Model (7) with data impreciseness. Since the year (2015) is observed and given to us, Model (2) can drop the data impreciseness while Model (7) handles the data (2015) as an imprecise data set for our comparison. The sample sets (2003-2015) are used for forecasting from 2016 and 2020 in this study.

(a) The observed data set contains observations from 2003 to 2015. The forecasted data set contains estimated observations from 2016-2020.

(b) The observations in 2015 are used for methodological comparison between the two cases: (2015 as an observed data set and 2015 as an estimated data set). The comparison provides us with information on how the proposed approach can improve the level of DEA performance assessment.

(a) Inputs are total assets and operating expenses; desirable outputs are total revenue and total enterprise value; and an undesirable output is $\mathrm{CO}_{2}$ emissions.

(b) The observations on each factor are divided by the mean to standardize the scale so that they are unit-less.

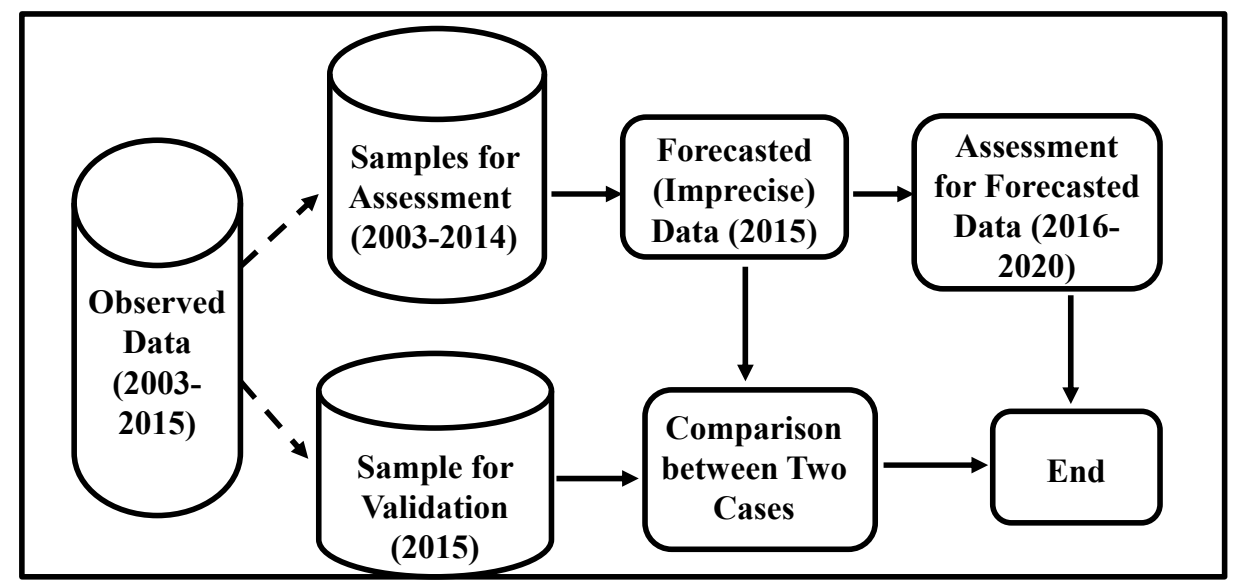

Figure 2. Methodological comparison and forecasting.

Figure 3 visually specifies regions from north to south where energy utility firms provide electricity. There are ten electric power firms in Japan. Okinawa Electric Power Company is excluded from the data sample because it is much smaller than the other nine utilities in terms of their business scales. 


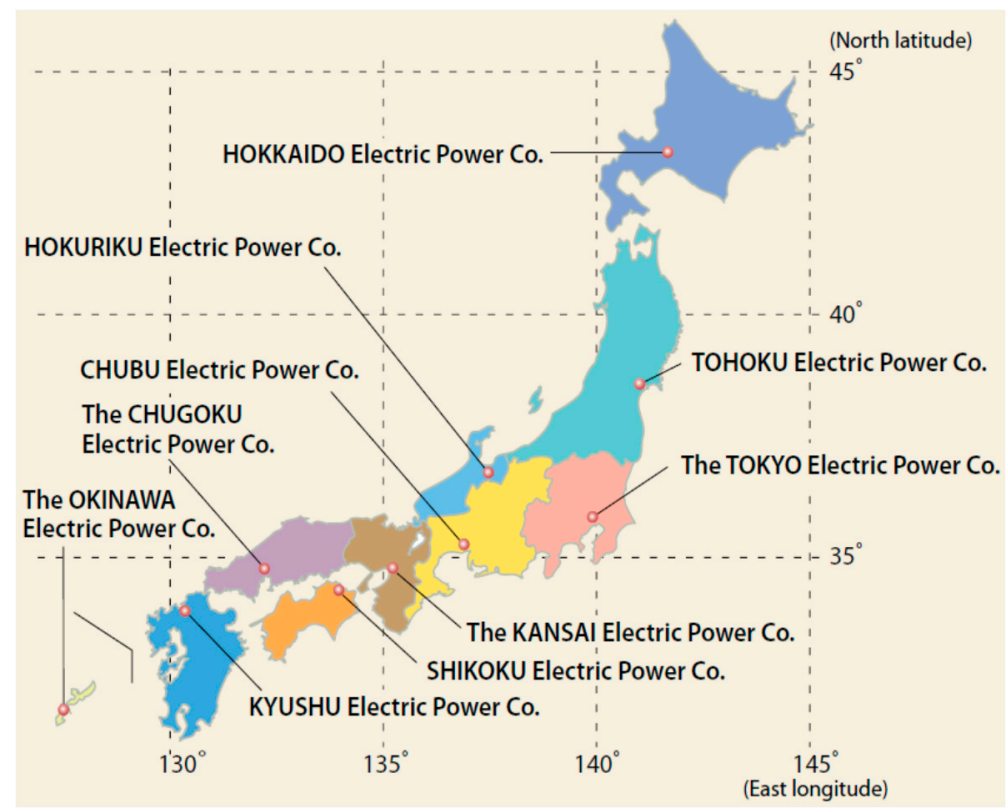

Figure 3. Ten electric power companies by service area. (Source: Electricity Review Japan, The Federation of Electric Power Companies of Japan 2012.)

Table 2 presents a TEPCO data set from 2003 to 2015 as an illustrative example of Japanese electric power companies. We obtained the data set from Japan's Federation of Electric Power Companies and the annual reports of the energy utility company. The observations on each factor are divided by each mean to standardize their scales. The adjustment is important in avoiding the case where a large data usually dominates a computation process, thus producing unreliable results.

Table 2. Tokyo Electric Power Company (2003-2015): An Example of Japanese Electric Power Companies

\begin{tabular}{cccccc}
\hline & Total Assets & $\begin{array}{c}\text { Operating } \\
\text { Expenses }\end{array}$ & Total Revenue & $\begin{array}{c}\text { Total Enterprise } \\
\text { Value }\end{array}$ & $\mathbf{C O}_{\mathbf{2}}$ Emissions \\
\hline 2003 & 3.0170 & 2.5329 & 2.5671 & 3.1517 & 2.8503 \\
2004 & 2.9422 & 2.5330 & 2.6164 & 3.2910 & 2.4469 \\
2005 & 2.9266 & 2.5888 & 2.6915 & 3.4564 & 2.4043 \\
2006 & 2.9024 & 2.6494 & 2.7603 & 3.4528 & 2.1870 \\
2007 & 2.9325 & 3.0377 & 2.8497 & 3.0952 & 2.8346 \\
2008 & 2.9173 & 3.3116 & 3.0648 & 3.1035 & 2.7046 \\
2009 & 2.8393 & 2.6861 & 2.6169 & 3.0096 & 2.4088 \\
2010 & 3.2016 & 2.8195 & 2.8060 & 2.8866 & 2.4626 \\
2011 & 3.4022 & 3.1840 & 4.1533 & 2.1241 & 2.7875 \\
2012 & 3.2833 & 3.5493 & 3.6189 & 2.1383 & 3.1640 \\
2013 & 3.2271 & 3.6924 & 4.4804 & 2.0839 & 2.1684 \\
2014 & 3.0829 & 3.7313 & 4.0774 & 1.9185 & 2.7695 \\
2015 & 2.9621 & 3.2740 & 3.6454 & 1.9468 & 2 \\
\hline
\end{tabular}

An important finding in Table 2 is that TEPCO has drastically reduced in corporate value from 2011 after the Great East Japan Earthquake generated a huge tsunami that caused damage to the northern part of Japan in March 2011, causing an exceptional disaster at the Fukushima Daiichi nuclear power plants. Since then, the electric utility firm has been operating as a public entity controlled by the Japanese government.

Research expectation: Before our DEA application, we expected that the company performed insufficiently after the nuclear disaster and would have a difficulty in improving the business status in future performance assessment. Such an expectation has initiated this study. 


\subsection{Primary Study}

The production factors of the Japanese electric power companies include (i) inputs, comprising (i-1) total assets and (i-2) the amount of operating expenses; (ii) desirable outputs, comprising (ii-1) total revenues and (ii-2) total enterprise values; and (iii) an undesirable output, which is the amount of $\mathrm{CO}_{2}$ emissions. The observed annual periods are from 2003 to 2015.

Table 3 summarizes the descriptive statistics of all nine electric power companies during the annual periods (2003-2015). They are divided by the mean to standardize their scales. Due to a space limit, this study lists only four annual periods $(2003,2007,2011$ and 2015) along with the averages of all electric power firms. Here, the average of each observed factor implies that the sum of these observations is divided by the number of annual periods (2003-2015). The statistics provide a whole view on the data set.

Table 3. Descriptive Statistics (2003-2015): Average.

\begin{tabular}{|c|c|c|c|c|c|c|c|c|c|c|}
\hline Year & Production Factors & Hokkaido & Tohoku & Tokyo & Chubu & Hokuriku & Kansai & Chugoku & Shikoku & Kyushu \\
\hline \multirow{4}{*}{2003} & Total Assets & 0.3081 & 0.8566 & 3.0170 & 1.2973 & 0.3442 & 1.4689 & 0.5657 & 0.3014 & 0.8667 \\
\hline & Operating Expenses & 0.2541 & 0.7618 & 2.5329 & 1.0135 & 0.2310 & 1.2149 & 0.4847 & 0.2701 & 0.6687 \\
\hline & Total Revenue & 0.2805 & 0.7817 & 2.5671 & 1.0937 & 0.2383 & 1.2869 & 0.4971 & 0.2766 & 0.7126 \\
\hline & $\mathrm{CO}_{2}$ Emissions & 0.3428 & 0.7892 & 2.8503 & 1.2855 & 0.2653 & 0.8192 & 0.8302 & 0.2306 & 0.5355 \\
\hline \multirow{3}{*}{2007} & Total Assets & 0.3270 & 0.8255 & 2.9325 & 1.1765 & 0.3326 & 1.3778 & 0.5671 & 0.3064 & 0.8500 \\
\hline & Operating Expenses & 0.3004 & 0.9169 & 3.0377 & 1.2195 & 0.2639 & 1.3615 & 0.5634 & 0.3008 & 0.7610 \\
\hline & $\mathrm{CO}_{2}$ Emissions & 0.3760 & 0.8916 & 2.8346 & 1.4491 & 0.4149 & 1.2322 & 0.9651 & 0.2568 & 0.7641 \\
\hline \multirow{5}{*}{2011} & Total Assets & 0.3489 & 0.8702 & 3.4022 & 1.2072 & 0.3050 & 1.4958 & 0.6039 & 0.2949 & 0.9232 \\
\hline & Operating Expenses & 0.3695 & 0.9683 & 3.1840 & 1.3751 & 0.2839 & 1.6202 & 0.6196 & 0.3184 & 0.9395 \\
\hline & Total Revenue & 0.3337 & 0.8039 & 4.1533 & 1.2532 & 0.2658 & 1.3655 & 0.6086 & 0.2945 & 0.7627 \\
\hline & Total Enterprise Value & 0.3224 & 0.7138 & 2.1241 & 1.0259 & 0.2909 & 1.3179 & 0.6189 & 0.3162 & 0.7054 \\
\hline & $\mathrm{CO}_{2}$ Emissions & 0.3502 & 0.9232 & 2.7875 & 1.4856 & 0.4151 & 1.4730 & 0.9251 & 0.3520 & 0.9636 \\
\hline \multirow{5}{*}{ Ave. } & Total Assets & 0.3477 & 0.8505 & 3.0490 & 1.1928 & 0.3240 & 1.4501 & 0.5892 & 0.3012 & 0.8956 \\
\hline & Operating Expenses & 0.3305 & 0.9198 & 3.0454 & 1.2637 & 0.2654 & 1.4545 & 0.5865 & 0.3016 & 0.8326 \\
\hline & Total Revenue & 0.3094 & 0.8805 & 3.2268 & 1.2579 & 0.2602 & 1.3996 & 0.5789 & 0.2958 & 0.7910 \\
\hline & Total Enterprise Value & 0.3576 & 0.8855 & 2.7430 & 1.2637 & 0.3512 & 1.5251 & 0.6532 & 0.3395 & 0.8812 \\
\hline & $\mathrm{CO}_{2}$ Emissions & 0.3791 & 0.8880 & 2.6998 & 1.3773 & 0.3378 & 1.2647 & 0.9299 & 0.2986 & 0.8248 \\
\hline
\end{tabular}

At the first step of this primary study, we pooled data from 2003 to 2015 into a single data set and applied Model (2). In this case, Model (2) did not incorporate data impreciseness because they were observed data. Table 4 summarizes the unified efficiency (UEN) measures of the nine electric power companies from 2003 to 2015. Figure 4 visually describes the annual shift of their unified efficiencies. As summarized in Table 4 and Figure 4, they performed well until 2010, but they declined after 2011 when the disaster of the Fukushima Daiichi nuclear power plants occurred on March 11 2011. As depicted in Figure 4, since the occurrence, Japanese electric power companies have suffered from the damage due to the nuclear disaster. 
Table 4. Unified Efficiency of Electric Power Companies: Pooled Data (2003-2015).

\begin{tabular}{cccccccccc}
\hline Year & Hokkaido & Tohoku & Tokyo & Chubu & Hokuriku & Kansai & Chugoku & Shikoku & Kyushu \\
\hline 2003 & 1.000 & 0.963 & 1.000 & 1.000 & 1.000 & 1.000 & 0.988 & 1.000 & 0.990 \\
2004 & 1.000 & 0.921 & 0.990 & 1.000 & 1.000 & 0.990 & 1.000 & 1.000 & 0.961 \\
2005 & 0.954 & 0.943 & 1.000 & 1.000 & 1.000 & 0.984 & 0.995 & 0.977 & 0.930 \\
2006 & 0.989 & 0.966 & 1.000 & 1.000 & 0.992 & 0.982 & 1.000 & 1.000 & 0.931 \\
2007 & 0.926 & 0.960 & 1.000 & 1.000 & 1.000 & 0.966 & 1.000 & 1.000 & 0.931 \\
2008 & 0.813 & 0.953 & 1.000 & 0.977 & 1.000 & 0.974 & 0.975 & 1.000 & 0.896 \\
2009 & 0.889 & 0.916 & 0.923 & 0.928 & 1.000 & 0.957 & 0.960 & 1.000 & 0.888 \\
2010 & 0.931 & 0.906 & 0.924 & 0.899 & 1.000 & 0.937 & 1.000 & 1.000 & 0.864 \\
2011 & 0.860 & 0.777 & 1.000 & 0.832 & 0.879 & 0.818 & 0.923 & 1.000 & 0.704 \\
2012 & 0.717 & 0.801 & 0.892 & 0.838 & 0.855 & 0.785 & 0.896 & 1.000 & 0.686 \\
2013 & 0.754 & 0.938 & 1.000 & 0.916 & 0.862 & 0.905 & 0.955 & 1.000 & 0.872 \\
2014 & 0.841 & 1.000 & 0.989 & 1.000 & 0.892 & 0.927 & 0.936 & 0.997 & 0.863 \\
2015 & 0.881 & 0.983 & 0.954 & 1.000 & 0.851 & 0.968 & 0.927 & 0.984 & 0.908 \\
Avg. & 0.889 & 0.925 & 0.975 & 0.953 & 0.948 & 0.938 & 0.966 & 0.997 & 0.879 \\
\hline
\end{tabular}

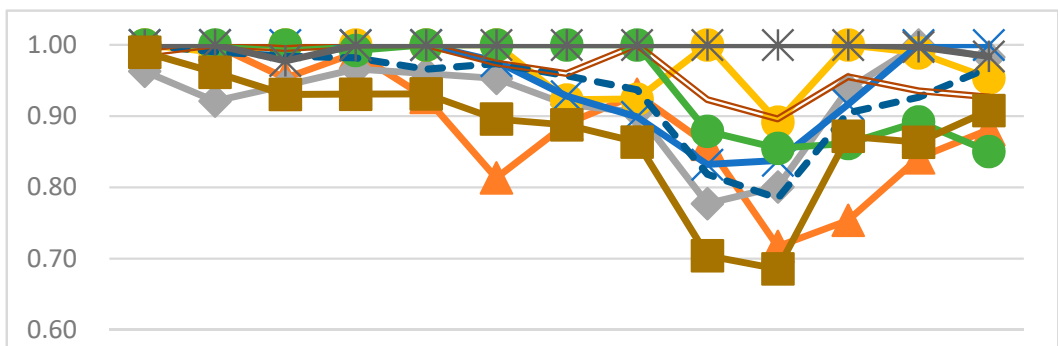

2003200420052006200720082009201020112012201320142015

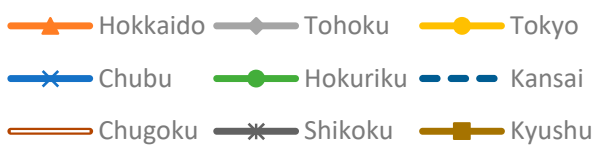

Figure 4. Annual shift of unified efficiencies of electric power companies.

\subsection{Handling Imprecise Data from 2015}

Using the data set shown Table 3, this study have considered two approaches to handle imprecise data, as depicted in Figure 2. First, we used data for the nine electric power companies in 2015 only. In this case, all observations did not have data impreciseness, so we dropped the symbol $(\sim)$ in the formulation of Model (2). Second, we used a forecasting technique (e.g., exponential smoothing) to estimate the performance of the nine utility firms in 2015 by using the data set from 2003 to 2014 . Exponential smoothing was used in this comparison to smooth the constants between 0 and 1 for forecasting. We used 0.1 and 0.9 for the prediction. Thus, we obtained their upper and lower bounds on the performance estimates of the nine electric power firms in 2015. We applied Model (7) to the predicted data set from 2015. The purpose of this comparison is to examine whether any difference occurs between the data with and without data impreciseness.

Exponential Smoothing: The forecasting method is specified here. The forecasted three production factors become the following equations:

$$
\begin{gathered}
F x_{i j t}=\alpha x_{i j t}+(1-\alpha) F x_{i j t-1} \quad(i=1, \ldots, m, j=1, \ldots, n \& t=2004, \ldots, 2015), \\
F g_{r j t}=\alpha g_{r j t}+(1-\alpha) F g_{r j t-1} \\
F b_{f j t}=\alpha b_{f j t}+(1-\alpha) F b_{f j t-1} \quad(f=1, \ldots, s, j=1, \ldots, n \& t=2004, \ldots, 2015) \\
\end{gathered}
$$

In Equation (9), the symbols $F x, F g$, and $F b$ on the left-hand side indicate the forecasted values of the three factors in the $t$ th period. This study used the mean between the upper and lower bounds of each factor to determine the unified efficiency from the forecasted data. The right-hand side indicates those in the $t=1$ period and observed data in the $t$ th period. The initial value of each factor 
$\left(F x_{i j 2003}, F g_{r j 2003}, F b_{f j 2003}\right)$ was calculated by the average of the factor during the former half period (i.e., from 2003 to 2008). The value $\alpha(0<\alpha<1)$ is referred to as a "smoothing constant." Thus, the forecasting for the th period is simply the weighted sum of the observations and the predicted values from the first to the last period. To enhance the computational tractability, this study has used Stata ver.14 econometric software, which incorporates a single exponential smoothing method.

Table 5 summarizes the two estimated values for the production factors of the nine electric power companies for 2015. The data columns in Table 5 summarize observed data for the nine electric utility firms in 2015. The columns with $\alpha=0.1$ and $\alpha=0.9$ indicate the forecasted data with the two smoothing constants, both of which were measured by the exponential smoothing technique.

Table 5. Observed and Predicted Values by Exponential Smoothing (2015).

\begin{tabular}{|c|c|c|c|c|c|c|c|c|c|}
\hline & Hokkaido & & & Tohoku & & & Tokyo & & \\
\hline & Data & $\alpha=0.1$ & $\alpha=0.9$ & Data & $\alpha=0.1$ & $\alpha=0.9$ & Data & $\alpha=0.1$ & $\alpha=0.9$ \\
\hline Total Assets & 0.3964 & 0.3443 & 0.3920 & 0.8628 & 0.8503 & 0.8677 & 2.9621 & 3.0515 & 3.0980 \\
\hline Total Revenue & 0.3767 & 0.3052 & 0.3573 & 1.0118 & 0.8770 & 1.0605 & 3.6454 & 3.2186 & 4.1095 \\
\hline Total Enterprise Value & 0.4081 & 0.3552 & 0.3935 & 0.9231 & 0.8882 & 0.9281 & 1.9468 & 2.8040 & 1.9356 \\
\hline \multirow[t]{2}{*}{$\mathrm{CO}_{2}$ Emissions } & 0.4293 & 0.3814 & 0.4574 & 0.9360 & 0.8883 & 0.9850 & 2.7696 & 2.7069 & 2.9341 \\
\hline & Data & $\alpha=0.1$ & $\alpha=0.9$ & Data & $\alpha=0.1$ & $\alpha=0.9$ & Data & $\alpha=0.1$ & $\alpha=0.9$ \\
\hline Total Assets & 1.1376 & 1.1985 & 1.1811 & 0.3277 & 0.3244 & 0.3184 & 1.4447 & 1.4506 & 1.5231 \\
\hline Operating Expenses & 1.3871 & 1.2646 & 1.6165 & 0.2781 & 0.2656 & 0.2856 & 1.5609 & 1.4585 & 1.8394 \\
\hline Total Revenue & 1.4415 & 1.2528 & 1.5704 & 0.2680 & 0.2604 & 0.2774 & 1.5710 & 1.3945 & 1.6520 \\
\hline Total Enterprise Value & 1.1165 & 1.2841 & 1.0568 & 0.3074 & 0.3564 & 0.2955 & 1.5220 & 1.5285 & 1.4518 \\
\hline $\mathrm{CO}_{2}$ Emissions & 1.3294 & 1.3829 & 1.3907 & 0.4168 & 0.3364 & 0.4038 & 1.4576 & 1.2644 & 1.6050 \\
\hline Operating Expenses & 0.6453 & 0.5854 & 0.6663 & 0.3374 & 0.3004 & 0.3348 & 0.9554 & 0.8281 & 1.0693 \\
\hline Total Revenue & 0.6324 & 0.5778 & 0.6657 & 0.3217 & 0.2955 & 0.3246 & 0.9336 & 0.7848 & 0.9581 \\
\hline Total Enterprise Value & 0.6829 & 0.6521 & 0.6498 & 0.3177 & 0.3420 & 0.2969 & 1.0054 & 0.8779 & 0.9761 \\
\hline $\mathrm{CO}_{2}$ Emissions & 0.9277 & 0.9323 & 0.9621 & 0.3861 & 0.2941 & 0.4022 & 0.9366 & 0.8235 & 1.0965 \\
\hline
\end{tabular}

(a) The data is originally observed in 2015.

(b) The selected smoothing constants 0.1 and 0.9 do not necessarily correspond to the lower and upper bounds of each production factor estimates. The forecasting produces the data impreciseness in the production factor estimates $(\mathrm{X}, \mathrm{G}$ and $\mathrm{B})$.

Table 6 lists the unified efficiency measures for the nine electric power companies that were measured by Model (2) and applied to the observed data set in 2015. In this case, we did not incorporate the data impreciseness in Model (2). The last column of the table indicates those measures from Model (7) that were applied to the data set with impreciseness.

Table 6. Unified efficiency measures on electric power companies using 2015 data.

\begin{tabular}{ccc}
\hline & UEN & \\
\hline & Model (2) & Model (7) \\
\hline Hokkaido & 1.000 & 0.929 \\
Tohoku & 1.000 & 0.803 \\
Tokyo & 1.000 & 0.811 \\
Chubu & 1.000 & 0.771 \\
Hokuriku & 1.000 & 0.961 \\
Kansai & 1.000 & 0.783 \\
Chugoku & 1.000 & 0.823 \\
Shikoku & 1.000 & 1.000 \\
Kyushu & 1.000 & 0.855 \\
\hline
\end{tabular}


Table 6 indicates two important implications. The first result produced from Model (2) measures the UEN measures of Japanese electric power companies under a possible occurrence of UC. Model (2) was applied to an observed data set for the nine companies in 2015. The problem is that all firms produce unity (1.000) in their UEN measures. The result is "unacceptable" as a result of a performance assessment because no difference can be found in their efficiency measures. The second result from Table 6 was measured by Model (7), which computed the UEN measures under the same condition. The model used a forecasted data set in 2015 for the nine companies for our comparative study. The data set was obtained by the exponential smoothing method that was applied to the data sets from 2003 to 2014. As listed in the last column, Shikoku Electric Power Company reached unity in UEN, but the others did not attain the unity, rather indicating some level of inefficiency. As mathematically discussed in Section 4, Model (7) incorporates multiplier restrictions to deal with data impreciseness so that it can reduce the number of efficient DMUs as a by-product of eliminating data impreciseness. Thus, we confirm that Model (7) outperforms Model (2) in terms of efficiency measurement.

Computational note: Model (2) does not need any forecasted values. Meanwhile, Model (7) needs estimated values. The lower and upper bounds ( $L$ and $U$ ) on the multipliers are due to Equation (9).

(a) For our methodological comparison, we use Model (2) without data impreciseness. The dual formulation of (2) becomes Model (4). Both produce the same unified efficiency measures.

(b) Model (2) measures the degree of unified efficiency under natural disposability (UEN) under a possible occurrence of UC (e.g., an economic difficulty). The model uses an observed data set on the electric power companies from 2015. The result is listed in the second column.

(c) Model (7) measures the degree of UEN under UC. This model uses an estimated data set for 2015 on the electric power companies. The data set is obtained by the exponential smoothing method applied to the data from 2003 to 2014. The result is listed in the last column.

(d) As listed in the second column under Model (2), all firms exhibited unity (1.000) in their UEN measures. This result is unacceptable because we cannot classify them for their ranks.

(e) As listed in the last column, electric power companies (i.e., Shikoku) reached unity, but the others were showing some level of inefficiency. Model (7) incorporates a multiplier restriction to handle the data impreciseness. As a result of such a restriction, they can reduce the number of efficient DMUs from nine to one.

\subsection{Forecasted Performance Assessment from 2016 to 2020}

To obtain the forecasted values of each production factor from 2016 to 2020, this research applied the double-exponential smoothing technique to the data set. Double-exponential smoothing conducts the same procedure described in Equations (9), but the smoothing was applied to the smoothed (predicted) series obtained from the (single) exponential smoothing.

The procedure for an input $(x)$, for example, becomes

$$
F x_{i j t}^{d}=\alpha F x_{i j t}+(1-\alpha) F x_{i j t-1}^{d} \quad(i=1, \ldots, m, j=1, \ldots, n \& t=2004, \ldots, 2020) .
$$

where the superscript $d$ stands for the double-exponential. In Equation (9), $F x_{i j t}^{d}$ on the left-hand side indicates the double-exponential smoothing forecast values for $x$ in the th period. The initial value $F x_{i j 2003}^{d}$ is obtained by fitting a linear regression with a time trend using the first half of the observations in the data set from 2003 to 2008.

Computational note: The proposed procedure can be applied to the other production factors $(g$, a desirable output and $b$, an undesirable output). Here, let us express the average of each factor of the $j$ th DMU by the bar (-). Then, $\bar{x}_{i j t}=\left(x_{i j t}^{L}+x_{i j t}^{U}\right) / 2, \bar{g}_{r j t}=\left(g_{r j t}^{L}+g_{r j t}^{U}\right) / 2$ and $\bar{b}_{f j t}=\left(b_{f j t}^{L}+b_{f j t}^{U}\right) / 2$, where the upper and lower bounds are due to Equation (10). These forecasted average values are used as the estimates of production factors in Model (7). 
Table 7 summarizes the forecasted values on $X, G$ and $B$ of the nine electric power companies in the case of $\alpha=0.1$ and 0.9 , along with the average (listed as "estimated") between the two forecasted values. Table 8 summarizes the unified efficiency measures of the nine electric power companies from 2016 to 2020. We applied Model (7) to the forecasted data set in Table 7, in the column named "estimated". In this case, each specific period was selected from 2016 to 2020. Note that the table summarizes their unified efficiency measures after we pools all data from 2016 to 2020. The predicted observations during the five years are treated as cross-sectional data. Figure 5 exhibits an annual shift of their unified efficiency measures. Table 9 summarizes the unified efficiency measures of the electric utility companies whose data sets are all pooled from 2016 to 2020.

We identify three main findings from Tables 8 and 9 and Figure 5. First, we cannot find any major difference between the two tables, indicating that the specific year and the pooled years do not produce a major difference in their computation of Model (7). As depicted in Figure 5, the Japanese electric power companies, e.g., Hokuriku, have improved their efficiency measures. The Hokuriku Electric Power Company showed a decreasing trend in 2016-2020. Second, the Shikoku Electric Power Company outperformed the others. Like Hokuriku, this power company is relatively small compared to the others; thus, it is expected that the firm controls the input measures (e.g., operation expenses) so that it could attain a high level of efficiency status. Finally, we expected TEPCO to perform very poorly because of the influence of the nuclear disaster. However, the performance of the firm was not the worst, rather being in the middle of the industry. See the results from the observed and forecasted data sets, as depicted in Figures 4 and 5; this is a surprising result.

Here, it is important to discuss concerning why TEPCO have performed relatively well needs to be discussed here. There are three rationales on the matter. First, the company covers Kanto area, including Tokyo and other large cities like Yokohama (the second largest city next Tokyo). Tokyo is the center of Japanese business, politics and all other activities. The company covers more than 30 million peoples. After the nuclear disaster, all electric power firms have suffered from declines of share prices, but have gradually regained their economic successes due to the new economic, energy and industrial strategies of the Japanese government since 2012. As a result, TEPCO can enjoy its scale merit in a recovery process from the nuclear disaster. Second, the Japanese government has created a policy scheme to allocate the huge loss from the nuclear disaster to not only TEPCO but also all the other incumbent electric power companies that own nuclear power plants. They have increased their electric tariffs so that they have gradually recovered from the financial damage by the support scheme through which they indirectly collect the costs from consumers and tax payers. Finally, the Japanese government has estimated a huge financial support for TEPCO over 20 to 30 years (approximately $\$ 203.4$ billion in total that is calculated by the exchange rate with 108.14 Japanese Yen per US dollar) to avoid the bankruptcy. The decision protected Japanese banks that had been supporting the operation of TEPCO. See $[43,44]$ that provide detailed description on the three rationales. 
Table 7. Forecasted Measures of Electric Power Companies (2016-2020).

\begin{tabular}{|c|c|c|c|c|c|c|c|c|c|c|c|c|c|c|c|}
\hline & \multicolumn{3}{|c|}{ Total Assets } & \multicolumn{3}{|c|}{ Operating Expenses } & \multicolumn{3}{|c|}{ Total Revenue } & \multicolumn{3}{|c|}{ Total Enterprise Value } & \multicolumn{3}{|c|}{$\mathrm{CO}_{2}$ Emissions } \\
\hline & Estimated & $\alpha=0.1$ & $\alpha=0.9$ & Estimated & $\alpha=0.1$ & $\alpha=0.9$ & Estimated & $\alpha=0.1$ & $\alpha=0.9$ & Estimated & $\alpha=0.1$ & $\alpha=0.9$ & Estimated & $\alpha=0.1$ & $\alpha=0.9$ \\
\hline \multicolumn{16}{|l|}{ Hokkaido } \\
\hline 2016 & 0.4014 & 0.4018 & 0.4010 & 0.4192 & 0.4464 & 0.3921 & 0.3763 & 0.3572 & 0.3955 & 0.4071 & 0.3925 & 0.4216 & 0.4315 & 0.4569 & 0.4061 \\
\hline 2017 & 0.4075 & 0.4095 & 0.4056 & 0.4266 & 0.4636 & 0.3896 & 0.3889 & 0.3636 & 0.4141 & 0.4163 & 0.3976 & 0.4350 & 0.4253 & 0.4679 & 0.3826 \\
\hline 2018 & 0.4137 & 0.4172 & 0.4101 & 0.4339 & 0.4807 & 0.3871 & 0.4014 & 0.3701 & 0.4328 & 0.4256 & 0.4027 & 0.4485 & 0.4190 & 0.4788 & 0.3592 \\
\hline 2019 & 0.4198 & 0.4249 & 0.4147 & 0.4412 & 0.4978 & 0.3846 & 0.4140 & 0.3765 & 0.4514 & 0.4349 & 0.4078 & 0.4619 & 0.4128 & 0.4898 & 0.3358 \\
\hline 2020 & 0.4259 & 0.4326 & 0.4192 & 0.4486 & 0.5150 & 0.3821 & 0.4265 & 0.3830 & 0.4700 & 0.4441 & 0.4129 & 0.4754 & 0.4065 & 0.5007 & 0.3123 \\
\hline \multicolumn{16}{|l|}{ Tohoku } \\
\hline 2016 & 0.8472 & 0.8381 & 0.8563 & 1.0757 & 1.1696 & 0.9818 & 1.0070 & 1.0330 & 0.9810 & 0.8682 & 0.8118 & 0.9247 & 0.9502 & 1.0077 & 0.8926 \\
\hline 2017 & 0.8424 & 0.8348 & 0.8499 & 1.0762 & 1.2085 & 0.9438 & 1.0019 & 1.0548 & 0.9489 & 0.8626 & 0.7996 & 0.9257 & 0.9369 & 1.0246 & 0.8492 \\
\hline 2018 & 0.8376 & 0.8315 & 0.8436 & 1.0766 & 1.2474 & 0.9058 & 0.9967 & 1.0766 & 0.9168 & 0.8570 & 0.7873 & 0.9267 & 0.9236 & 1.0414 & 0.8058 \\
\hline 2019 & 0.8327 & 0.8282 & 0.8373 & 1.0771 & 1.2864 & 0.8678 & 0.9915 & 1.0984 & 0.8847 & 0.8514 & 0.7751 & 0.9277 & 0.9103 & 1.0583 & 0.7624 \\
\hline 2020 & 0.8279 & 0.8249 & 0.8310 & 1.0775 & 1.3253 & 0.8298 & 0.9864 & 1.1202 & 0.8526 & 0.8458 & 0.7629 & 0.9287 & 0.8971 & 1.0751 & 0.7190 \\
\hline \multicolumn{16}{|l|}{ Tokyo } \\
\hline 2016 & 2.9444 & 3.0497 & 2.8391 & 3.4316 & 3.9434 & 2.9199 & 3.6413 & 4.0301 & 3.2524 & 2.0696 & 2.1996 & 1.9396 & 2.7352 & 2.8547 & 2.6158 \\
\hline 2017 & 2.8808 & 3.0454 & 2.7163 & 3.3201 & 4.0796 & 2.5606 & 3.4968 & 4.1366 & 2.8569 & 2.0372 & 2.1401 & 1.9342 & 2.6667 & 2.8708 & 2.4627 \\
\hline 2018 & 2.8172 & 3.0411 & 2.5934 & 3.2086 & 4.2158 & 2.2013 & 3.3522 & 4.2430 & 2.4615 & 2.0047 & 2.0807 & 1.9287 & 2.5982 & 2.8869 & 2.3095 \\
\hline 2019 & 2.7537 & 3.0368 & 2.4705 & 3.0970 & 4.3520 & 1.8421 & 3.2077 & 4.3495 & 2.0660 & 1.9723 & 2.0213 & 1.9233 & 2.5297 & 2.9030 & 2.1563 \\
\hline 2020 & 2.6901 & 3.0325 & 2.3476 & 2.9855 & 4.4882 & $\begin{array}{l}1.4828 \\
\text {. }\end{array}$ & 3.0632 & 4.4559 & 1.6706 & 1.9398 & 1.9618 & 1.9178 & 2.4611 & 2.9192 & 2.0031 \\
\hline \multicolumn{16}{|l|}{ Chubu } \\
\hline 2016 & 1.0867 & 1.0751 & 1.0984 & 1.4202 & 1.6308 & 1.2097 & 1.4280 & 1.5025 & 1.3535 & 1.0429 & 0.9216 & 1.1643 & 1.3810 & 1.4887 & 1.2733 \\
\hline 2017 & 1.0571 & 1.0549 & 1.0592 & 1.3568 & 1.6842 & 1.0294 & 1.3996 & 1.5365 & 1.2627 & 1.0424 & 0.8722 & 1.2126 & 1.3622 & 1.5072 & 1.2173 \\
\hline 2018 & $\begin{array}{l}1.0274 \\
\text { S }\end{array}$ & 1.0348 & 1.0200 & 1.2934 & 1.7376 & 0.8492 & $\begin{array}{l}1.3712 \\
\text {. }\end{array}$ & 1.5704 & 1.1719 & $\begin{array}{l}1.0419 \\
\text { a }\end{array}$ & 0.8229 & $\begin{array}{l}1.2609 \\
\text { a }\end{array}$ & 1.3434 & 1.5256 & 1.1613 \\
\hline 2019 & 0.9977 & 1.0147 & 0.9808 & 1.2299 & 1.7910 & 0.6689 & 1.3428 & 1.6044 & 1.0812 & 1.0414 & 0.7736 & 1.3093 & 1.3246 & 1.5440 & 1.1052 \\
\hline 2020 & 0.9680 & 0.9945 & 0.9416 & 1.1665 & 1.8444 & 0.4886 & 1.3143 & 1.6383 & 0.9904 & 1.0410 & 0.7243 & 1.3576 & 1.3058 & 1.5624 & $\begin{array}{l}1.0492 \\
\text { l }\end{array}$ \\
\hline \multicolumn{16}{|c|}{ Hokuriku } \\
\hline 2016 & 0.3153 & 0.2952 & 0.3354 & 0.2976 & 0.3231 & 0.2722 & 0.2762 & 0.2909 & 0.2614 & 0.3116 & 0.3054 & 0.3178 & 0.4537 & 0.4798 & 0.4275 \\
\hline 2017 & 0.3169 & 0.2906 & 0.3433 & 0.2992 & 0.3324 & 0.2661 & 0.2752 & 0.2958 & 0.2546 & 0.3144 & 0.3004 & 0.3283 & 0.4700 & 0.5015 & 0.4384 \\
\hline 2018 & 0.3185 & 0.2859 & 0.3511 & 0.3009 & 0.3417 & 0.2601 & 0.2743 & 0.3008 & 0.2479 & 0.3171 & 0.2954 & 0.3387 & 0.4862 & 0.5232 & 0.4493 \\
\hline 2019 & 0.3201 & 0.2812 & 0.3590 & 0.3025 & 0.3510 & 0.2540 & 0.2734 & 0.3057 & 0.2411 & 0.3198 & 0.2904 & 0.3492 & 0.5025 & 0.5449 & 0.4602 \\
\hline 2020 & 0.3217 & 0.2765 & 0.3668 & 0.3041 & 0.3603 & 0.2480 & 0.2725 & 0.3106 & 0.2343 & 0.3226 & 0.2855 & 0.3597 & 0.5188 & 0.5665 & 0.4710 \\
\hline
\end{tabular}


Table 7. Cont

\begin{tabular}{|c|c|c|c|c|c|c|c|c|c|c|c|c|c|c|c|}
\hline & \multicolumn{3}{|c|}{ Total Assets } & \multicolumn{3}{|c|}{ Operating Expenses } & \multicolumn{3}{|c|}{ Total Revenue } & \multicolumn{3}{|c|}{ Total Enterprise Value } & \multicolumn{3}{|c|}{$\mathrm{CO}_{2}$ Emissions } \\
\hline & Estimated & $\alpha=0.1$ & $\alpha=0.9$ & Estimated & $\alpha=0.1$ & $\alpha=0.9$ & Estimated & $\alpha=0.1$ & $\alpha=0.9$ & Estimated & $\alpha=0.1$ & $\alpha=0.9$ & Estimated & $\alpha=0.1$ & $\alpha=0.9$ \\
\hline \multicolumn{16}{|l|}{ Kansai } \\
\hline 2016 & 1.4039 & 1.4280 & 1.3798 & 1.5807 & 1.8160 & 1.3455 & 1.5352 & 1.5563 & 1.5140 & 1.4618 & 1.3459 & 1.5777 & 1.4891 & 1.6417 & 1.3366 \\
\hline 2017 & 1.3679 & 1.4216 & 1.3143 & 1.4972 & 1.8679 & 1.1266 & 1.5159 & 1.5764 & 1.4555 & 1.4764 & 1.3186 & 1.6342 & 1.4545 & 1.6945 & 1.2145 \\
\hline 2018 & 1.3320 & 1.4152 & 1.2488 & 1.4137 & 1.9198 & 0.9077 & 1.4967 & 1.5965 & 1.3969 & 1.4909 & 1.2912 & 1.6906 & 1.4199 & 1.7474 & 1.0924 \\
\hline 2019 & 1.2961 & 1.4088 & 1.1833 & 1.3302 & 1.9716 & 0.6888 & 1.4774 & 1.6166 & 1.3383 & 1.5055 & 1.2638 & 1.7471 & 1.3852 & 1.8002 & 0.9702 \\
\hline 2020 & 1.2601 & 1.4025 & 1.1178 & 1.2467 & 2.0235 & 0.4699 & 1.4582 & 1.6367 & 1.2797 & 1.5200 & 1.2365 & 1.8036 & 1.3506 & 1.8531 & 0.8481 \\
\hline \multicolumn{16}{|l|}{ Chugoku } \\
\hline 2016 & 0.6349 & 0.6319 & 0.6379 & 0.6849 & 0.7421 & 0.6277 & 0.6506 & 0.6930 & 0.6083 & 0.7104 & 0.7113 & 0.7095 & 0.9692 & 1.0409 & 0.8975 \\
\hline 2017 & 0.6375 & 0.6375 & 0.6376 & 0.6880 & 0.7661 & 0.6099 & 0.6469 & 0.7101 & 0.5836 & 0.7290 & 0.7216 & 0.7363 & 0.9632 & 1.0591 & 0.8673 \\
\hline 2018 & 0.6402 & 0.6430 & 0.6374 & 0.6911 & 0.7900 & 0.5921 & 0.6431 & 0.7273 & 0.5589 & 0.7475 & 0.7319 & 0.7631 & 0.9571 & 1.0772 & 0.8371 \\
\hline 2019 & 0.6428 & 0.6486 & 0.6371 & 0.6942 & 0.8140 & 0.5744 & 0.6393 & 0.7444 & 0.5342 & 0.7661 & 0.7423 & 0.7900 & 0.9511 & 1.0953 & 0.8069 \\
\hline 2020 & 0.6455 & 0.6541 & 0.6368 & 0.6973 & 0.8379 & 0.5566 & 0.6355 & 0.7615 & 0.5095 & 0.7847 & 0.7526 & 0.8168 & 0.9451 & 1.1134 & 0.7767 \\
\hline \multicolumn{16}{|l|}{ Shikoku } \\
\hline 2016 & 0.3046 & 0.3042 & 0.3049 & 0.3460 & 0.3521 & 0.3398 & 0.3264 & 0.3326 & 0.3201 & 0.3473 & 0.3608 & 0.3338 & 0.3730 & 0.3751 & 0.3710 \\
\hline 2017 & 0.3059 & 0.3048 & 0.3070 & 0.3509 & 0.3595 & 0.3422 & 0.3283 & 0.3383 & 0.3184 & 0.3583 & 0.3664 & 0.3502 & 0.3699 & 0.3837 & 0.3560 \\
\hline 2018 & 0.3073 & 0.3055 & 0.3090 & 0.3558 & 0.3669 & 0.3446 & 0.3303 & 0.3439 & 0.3167 & 0.3693 & 0.3720 & 0.3666 & 0.3667 & 0.3924 & 0.3410 \\
\hline 2019 & 0.3086 & 0.3061 & 0.3111 & 0.3607 & 0.3743 & 0.3470 & 0.3322 & 0.3495 & 0.3150 & 0.3803 & 0.3776 & 0.3830 & 0.3635 & 0.4011 & 0.3259 \\
\hline 2020 & 0.3099 & 0.3067 & 0.3132 & 0.3656 & 0.3818 & 0.3494 & 0.3342 & 0.3551 & 0.3133 & 0.3913 & 0.3832 & 0.3994 & 0.3603 & 0.4097 & 0.3109 \\
\hline \multicolumn{16}{|l|}{ Kyushu } \\
\hline 2016 & 0.9455 & 0.9261 & 0.9648 & 0.9560 & 1.0452 & 0.8668 & 0.9113 & 0.9047 & 0.9179 & 0.9677 & 0.9008 & 1.0347 & 0.9658 & 1.1289 & 0.8026 \\
\hline 2017 & 0.9435 & 0.9283 & 0.9586 & 0.9253 & 1.0739 & 0.7768 & 0.9103 & 0.9191 & 0.9016 & 0.9830 & 0.9022 & 1.0637 & 0.9195 & 1.1714 & 0.6676 \\
\hline 2018 & 0.9415 & 0.9305 & 0.9525 & 0.8947 & 1.1026 & 0.6868 & 0.9094 & 0.9335 & 0.8853 & 0.9982 & 0.9037 & 1.0927 & 0.8733 & 1.2140 & 0.5326 \\
\hline 2019 & 0.9395 & 0.9327 & 0.9463 & 0.8641 & 1.1313 & 0.5968 & 0.9085 & 0.9480 & 0.8690 & 1.0135 & 0.9052 & $\begin{array}{l}1.1218 \\
\text { S }\end{array}$ & 0.8271 & 1.2565 & 0.3976 \\
\hline 2020 & 0.9375 & 0.9349 & 0.9401 & 0.8334 & 1.1600 & 0.5068 & 0.9075 & 0.9624 & 0.8527 & 1.0287 & 0.9067 & 1.1508 & 0.7808 & 1.2990 & 0.2626 \\
\hline
\end{tabular}


Table 8. Unified Efficiency of Electric Power Companies (2016-2020).

\begin{tabular}{cccccccc}
\hline & $\mathbf{2 0 1 6}$ & $\mathbf{2 0 1 7}$ & $\mathbf{2 0 1 8}$ & $\mathbf{2 0 1 9}$ & $\mathbf{2 0 2 0}$ & Avg. & S.D. \\
\hline Hokkaido & 0.9206 & 0.9281 & 0.9354 & 0.9424 & 0.9492 & 0.9351 & 0.0113 \\
Tohoku & 0.8372 & 0.8543 & 0.8711 & 0.8874 & 0.8937 & 0.8687 & 0.0233 \\
Tokyo & 0.8192 & 0.8764 & 0.9085 & 0.9420 & 0.9838 & 0.9060 & 0.0628 \\
Chubu & 0.8461 & 0.8964 & 0.9350 & 0.9375 & 0.9421 & 0.9114 & 0.0408 \\
Hokuriku & 0.8944 & 0.8793 & 0.8659 & 0.8543 & 0.8443 & 0.8676 & 0.0199 \\
Kansai & 0.8327 & 0.8884 & 0.9427 & 0.9954 & 1.0000 & 0.9318 & 0.0716 \\
Chugoku & 0.8326 & 0.8478 & 0.8648 & 0.8801 & 0.8638 & 0.8578 & 0.0181 \\
Shikoku & 1.0000 & 1.0000 & 1.0000 & 1.0000 & 1.0000 & 1.0000 & 0.0000 \\
Kyushu & 0.8510 & 0.8851 & 0.9222 & 0.9582 & 0.9886 & 0.9210 & 0.0551 \\
\hline Avg. & 0.8704 & 0.8951 & 0.9162 & 0.9330 & 0.9406 & 0.9111 & 0.0337 \\
S.D. & 0.0586 & 0.0458 & 0.0444 & 0.0503 & 0.0599 & 0.0441 & 0.0249 \\
\hline Avg.
\end{tabular}

Avg. and S.D. re average and standard deviation, respectively. Model (7) uses estimated values measured by Equation (9). All are treated separately in this data analysis.

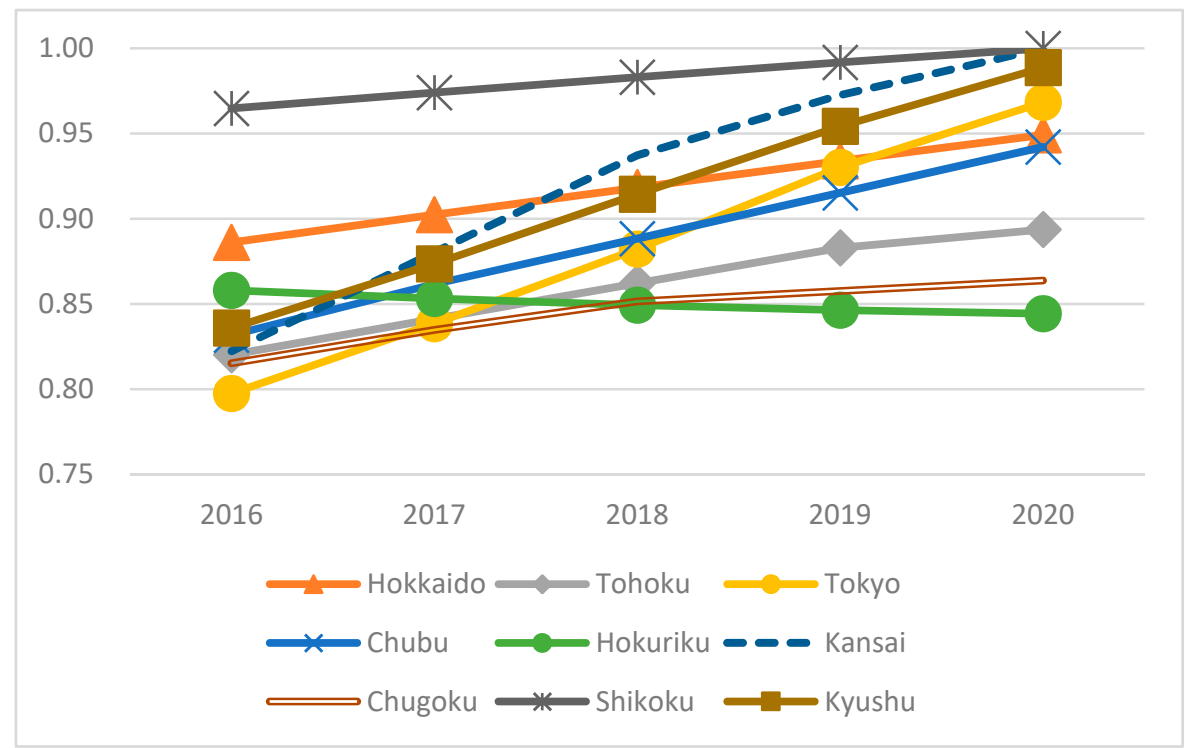

Figure 5. Annual shift of unified efficiencies of electric power companies: Pooled data from 2016 to 2020 .

Table 9. Unified Efficiency of Electric Power Companies: Pooled Data (2016-2020).

\begin{tabular}{cccccccc}
\hline & $\mathbf{2 0 1 6}$ & $\mathbf{2 0 1 7}$ & $\mathbf{2 0 1 8}$ & $\mathbf{2 0 1 9}$ & $\mathbf{2 0 2 0}$ & Avg. & S.D. \\
\hline Hokkaido & 0.8861 & 0.9024 & 0.9183 & 0.9339 & 0.9492 & 0.9180 & 0.0249 \\
Tohoku & 0.8202 & 0.8413 & 0.8622 & 0.8829 & 0.8937 & 0.8600 & 0.0300 \\
Tokyo & 0.7975 & 0.8385 & 0.8822 & 0.9301 & 0.9683 & 0.8833 & 0.0685 \\
Chubu & 0.8316 & 0.8617 & 0.8884 & 0.9152 & 0.9421 & 0.8878 & 0.0434 \\
Hokuriku & 0.8580 & 0.8532 & 0.8493 & 0.8464 & 0.8443 & 0.8502 & 0.0055 \\
Kansai & 0.8223 & 0.8805 & 0.9372 & 0.9726 & 1.0000 & 0.9225 & 0.0716 \\
Chugoku & 0.8152 & 0.8348 & 0.8515 & 0.8576 & 0.8638 & 0.8446 & 0.0197 \\
Shikoku & 0.9648 & 0.9741 & 0.9830 & 0.9918 & 1.0000 & 0.9827 & 0.0139 \\
Kyushu & 0.8359 & 0.8736 & 0.9144 & 0.9542 & 0.9886 & 0.9133 & 0.0611 \\
\hline Avg. & 0.8480 & 0.8733 & 0.8985 & 0.9205 & 0.9389 & 0.8958 & 0.0376 \\
S.D. & 0.0508 & 0.0438 & 0.0442 & 0.0501 & 0.0587 & 0.0437 & 0.0246 \\
\hline Avg.
\end{tabular}

Avg. and S.D. re average and standard deviation, respectively. Model (7) uses estimated values measured by Equation (10). All are pooled together in this data analysis. 


\section{Conclusions}

This study examined the performance of Japanese electric power companies from 2003 to 2020 where we used an observed data set on 2003-2015 and a forecasted data set on 2016-2020. As a method, this study used DEA environmental assessment. An important feature incorporated into the approach was originally designed to handle a production process among $X, G$ and $B$. The approach unified them into a holistic assessment without an assumption on a production function among them. This study newly added an analytical capability to the DEA-based assessment by including a capability to handle an "imprecise" data set for "future prediction". It is easily imagined that the forecasting is usually associated with data impreciseness. It is also true that most of data may be structured under the impreciseness.

As an important application, this study applied the proposed approach to investigate the Japanese electric power industry, including after the disaster of Fukushima Daiichi nuclear power plants. All the electric power firms have suffered from huge damage in their operations in 2011 due to the nuclear disaster. The Japanese government has developed a policy scheme for recovering the huge amount of nuclear accident handling costs due to the nuclear disaster, which has allocated the costs to not only TEPCO but also the other incumbent electric power utility companies that own nuclear power plants. Under the scheme, they have increased their electric tariffs so that their financial conditions have been gradually recovering from the damage by their managerial efforts and allocating the expenditure indirectly to consumers and tax payers. A policy issue to be discussed in future is how to minimize the total expenditures so that it can reduce people's financial burdens. For the purpose, the efficiency measurement is important as documented in this research.

We have the five research tasks, all of which were not sufficiently explored in this study. They become the future extensions of this study which are specified as follows: First, this study considers only the amount of $\mathrm{CO}_{2}$ emission as an undesirable output because its reduction is the main interest of the world. However, it is true that we need to consider the other types of GHG emissions (e.g., NOx: Nitrogen Oxides). Unfortunately, we had a difficulty in data accessibility on those undesirable outputs, so not incorporating them in this study. Second, the Japanese government still believes the nuclear power energy is necessary for the future industrial development and the reduction on GHG emissions. However, is it an appropriate policy direction? Such a policy question, including part of Japanese fuel mix strategy, needs to be discussed from future energy perspectives. Third, this study needs to discuss how to conduct various statistical tests based upon the proposed DEA environmental assessment on data impreciseness. Such analyses on the data impreciseness and forecasting will be an important future research task. Fourth, we need to extend this study by empirically applying the proposed approach to examine the influence of BEP. Finally, it is necessary for us to apply the proposed approach to the industrial assessment in not only Japan but also the other industrial nations.

In conclusion, it is hoped that this study makes a contribution on energy. We look forward to seeing future extensions as summarized above.

Author Contributions: Conceptualization, T.S.; methodology, T.S.; computation, M.G.; validation, T.S.; formal analysis, T.S.; investigation, T.S. and M.G.; resources, M.G.; data curation, M.G.; writing-original draft preparation, T.S.; writing-review and editing, T.S. and M.G.; visualization, T.S. and M.G.; supervision, T.S.; project administration, T.S.; funding acquisition, M.G. All authors have read and agreed to the published version of the manuscript.

Funding: This work was supported by a Japan Society for the Promotion of Science Grant-in-Aid for Scientific Research (KAKENHI) 19K04878.

Conflicts of Interest: The authors declare no conflict of interest. 


\section{Abbreviations}

\begin{tabular}{|c|c|}
\hline ARA & Assurance Region Analysis \\
\hline BEP & Basic Energy Plan \\
\hline $\mathrm{CO}_{2}$ & Carbon Dioxide \\
\hline DEA & Data Envelopment Analysis \\
\hline DMU & Decision Making Unit \\
\hline DTS & Damages to Scale \\
\hline EE & Energy Efficiency \\
\hline ENV & Environment \\
\hline GHG & Greenhouse Gas \\
\hline IPCC & Intergovernmental Panel on Climate Change \\
\hline KWh & Kirowatt hour \\
\hline METI & Ministry of Economy, Trade and Industry \\
\hline NOx & Nitrogen Oxides \\
\hline ОССТО & Organization for Cross-regional Coordination of Transmission Operators \\
\hline RES & Renewable Energy Sources \\
\hline RTS & Returns to Scale \\
\hline UE & Unified Efficiency \\
\hline UEN & Unified Efficiency under Natural disposability \\
\hline UEM & Unified Efficiency under Managerial disposability \\
\hline $\mathrm{UC}$ & Undesirable Congestion \\
\hline URS & Unrestricted \\
\hline TEPCO & Tokyo Electric Power Company \\
\hline TWh & Terawatt hour \\
\hline \multicolumn{2}{|l|}{ Variable } \\
\hline$X$ & A column vector of $m$ inputs \\
\hline G & A column vector of $s$ desirable outputs \\
\hline$B$ & A column vector of $h$ undesirable outputs \\
\hline$\xi$ & an inefficiency score \\
\hline$d_{i}^{x}$ & an unknown slack variable of the $i$ th input \\
\hline$d_{r}^{g}$ & an unknown slack variable of the $r$ th desirable output \\
\hline$d_{f}^{b}$ & an unknown slack variable of the $f$ th undesirable output \\
\hline$\lambda$ & an unknown column vector of intensity (or structural) variables \\
\hline$\varepsilon_{S}$ & a prescribed small number \\
\hline$v_{i}$ & a dual variable related to the $i$ th input \\
\hline$u_{r}$ & a dual variable related to the $r$ th desirable output \\
\hline$w_{f}$ & a dual variable related to the $f$ th undesirable output and \\
\hline$\sigma$ & a dual variable obtained from the constraint that the sum of $\lambda_{j}$ is unity \\
\hline
\end{tabular}

\section{References}

1. Sueypshi, T.; Goto, M. DEA radial measurement for environmental assessment: A comparative study between Japanese chemical and pharmaceutical firms. Appl. Energy 2014, 115, 502-513. [CrossRef]

2. Sueyoshi, T.; Goto, M. Environmental Assessment on Energy and Sustainability by Data Envelopment Analysis; John Wily \& Sons: London, UK, 2018.

3. Goto, M.; Sueyoshi, T. Electric power market reform in Japan after Fukushima Daiichi nuclear plant disaster: Issues and future direction. Int. J. Energy Sect. Manag. 2015, 9, 336-360. [CrossRef]

4. Goto, M.; Inoue, T.; Sueyoshi, T. Structural reform of Japanese electric power industry: Separation between generation and transmission \& distribution. Energy Policy 2013, 56, 186-200.

5. Goto, M.; Sueyoshi, T. Electricity market reform in Japan after Fukushima. Econ. Energy Environ. Policy 2016, 5, 15-30. [CrossRef]

6. Goto, M.; Takahashi, T. Operational and environmental efficiencies of Japanese electric power companies from 2003 to 2015: Influence of market reform and Fukushima nuclear power accident. Math. Probl. Eng. 2017, 2017, 1-15. [CrossRef] 
7. Tokyo Electric Power Company-Holdings 2019. Fact Book; Tokyo Electric Power Company Holdings, Inc.: Tokyo, Japan, 2019.

8. Tokyo Electric Power Company Holding. Available online: http://www.tepco.co.jp/corporateinfo/illustrated/ environment/emissions-co2-j.html (accessed on 1 January 2020).

9. Goto, M.; Sueyoshi, T. Productivity growth and deregulation of Japanese electricity distribution. Energy Policy 2009, 37, 3130-3138. [CrossRef]

10. Li, H.-Z.; Kopsakangas-Savolainen, M.; Xiao, X.-Z. Have regulatory reforms improved the efficiency levels of the Japanese electricity distribution sector? A cost metafrontier-based analysis. Energy Policy 2017, 108, 606-616. [CrossRef]

11. Sueyoshi, T.; Goto, M. Slack-adjusted DEA for time series analysis: Performance measurement of Japanese electrical power generation industry in 1984-1993. Eur. J. Oper. Res. 2001, 133, 232-259. [CrossRef]

12. Sueyoshi, T.; Goto, M. DEA approach for unified efficiency measurement: Assessment of Japanese fossil fuel power generation. Energy Econ. 2011, 33, 292-303. [CrossRef]

13. Sueyoshi, T.; Goto, M. Efficiency-based rank assessment for electric power industry: A combined use of data envelopment analysis (DEA) and DEA-discriminant analysis (DA). Energy Econ. 2012, 34, 634-644. [CrossRef]

14. Hosoe, N.; Tanaka, M. Divestiture of TEPCO for Reparation for the Fukushima nuclear accident: A path to vertical unbundling. Energy Policy 2012, 51, 207-212. [CrossRef]

15. Wang, N.; Mogi, G. From regulation to deregulation: An empirical study of Japanese electric utility R\&D investment behavior under transition. Energy Policy 2017, 105, 3193-3200.

16. Sueyoshi, T.; Yuan, Y.; Goto, M. A literature study for DEA applied to energy and environment. Energy Econ. 2017, 62, 104-124. [CrossRef]

17. Yang, H.; Pollitt, M. The necessity of distinguishing weak and strong disposability among undesirable outputs in DEA: Environmental performance of Chinese coal-fired power plants. Energy Policy 2010, 38, 4440-4444. [CrossRef]

18. Zhou, D.Q.; Wu, F.; Zhou, X.; Zhou, P. Output-specific energy efficiency assessment: A data envelopment analysis approach. Appl. Energy 2016, 177, 117-126. [CrossRef]

19. Zhang, Y.J.; Hao, J.F.; Song, J. The $\mathrm{CO}_{2}$ emission efficiency, reduction potential and spatial clustering in China's industry: Evidence from the regional level. Appl. Energy 2016, 174, 213-223. [CrossRef]

20. Du, H.; Matisoff, D.C.; Wang, Y.; Liu, X. Understanding drivers of energy efficiency changes in China. Appl. Energy 2016, 184, 1196-1206. [CrossRef]

21. Wu, J.; Zhu, Q.; Liang, L. $\mathrm{CO}_{2}$ emissions and energy intensity reduction allocation over provincial industrial sectors in China. Appl. Energy 2016, 166, 282-291. [CrossRef]

22. Wang, D.D. Do United States companies benefit from climate change mitigation technologies. J. Clean. Prod. 2017, 161, 821-830. [CrossRef]

23. Qin, Q.; Li, X.; Li, L.; Zhen, W.; Wei, Y.M. Air emissions perspective on energy efficiency: An empirical analysis of China's coastal areas. Appl. Energy 2017, 185, 604-614. [CrossRef]

24. Wang, D.D.; Sueyoshi, T. Assessment of large commercial rooftop photovoltaic system installations: Evidence from California. Appl. Energy 2017, 188, 45-55. [CrossRef]

25. Li, K.; Lin, B. Economic growth model, structural transformation, and green productivity in China. Appl. Energy 2017, 187, 489-500. [CrossRef]

26. Ji, X.; Li, G.; Wang, Z. Allocation of emission permits for China's power plants: A systemic Pareto optimal method. Appl. Energy 2017, 204, 607-619. [CrossRef]

27. Li, Y.; Cui, Q. Carbon neutral growth from 2020 strategy and airline environmental inefficiency: A Network Range Adjusted Environmental Data Envelopment Analysis. Appl. Energy 2017, 199, 13-24. [CrossRef]

28. Li, A.; Zhang, A.; Zhou, Y.; Yao, X. Decomposition analysis of factors affecting carbon dioxide emissions across provinces in China. J. Clean. Prod. 2017, 141, 1428-1444. [CrossRef]

29. Li, A.; Zhang, A.; Huang, H.; Yao, X. Measuring unified efficiency of fossil fuel power plants across provinces in China: An analysis based on non-radial directional distance functions. Energy 2018, 152, 549-561. [CrossRef]

30. Sun, C.; Liu, X.; Li, A. Measuring unified efficiency of Chinese fossil fuel power plants: Intermediate approach combined with group heterogeneity and window analysis. Energy Policy 2018, 123, 8-18. [CrossRef] 
31. Zhang, G.; Lin, B. Impact of structure on unified efficiency for Chinese service sector: A two-stage analysis. Appl. Energy 2018, 231, 876-886. [CrossRef]

32. Sueyoshi, T.; Goto, M. Resource utilization for sustainability enhancement in Japanese industries. Appl. Energy 2018, 228, 2308-2320. [CrossRef]

33. Wang, D.D. Assessing road transportation sustainability by combining environmental impacts and environmental concerns. Transp. Res. Part D 2019, 77, 212-223. [CrossRef]

34. Yu, A.; You, J.; Rudkin, S.; Zhang, H. Industrial carbon abatement allocations and regional collaboration: Reevaluating China through a modified data envelopment analysis. Appl. Energy 2019, 233-234, 232-243. [CrossRef]

35. Cooper, W.W.; Deng, H.; Huang, Z.; Li, S.X. Chance constrained programming approaches to congestion in stochastic data envelopment analysis. Eur. J. Oper. Res. 2004, 155, 487-501. [CrossRef]

36. Sueyoshi, T. Stochastic DEA for restructure strategy: An application to Japanese Petroleum Company. OMEGA 2000, 28, 385-398. [CrossRef]

37. Chen, T.Y. A Comparison of chance-constrained DEA and stochastic frontier analysis: Bank efficiency in Taiwan. J. Oper. Res. Soc. 2002, 53, 492-500. [CrossRef]

38. Cooper, W.W.; Huang, Z.; Lelas, V.; Li, S.X. Chance constrained programming formulations for stochastic characterizations of efficiency and dominance in DEA. J. Product. Anal. 1998, 9, 53-79. [CrossRef]

39. Kao, C.; Liu, S.T. A parallel production frontiers approach for intertemporal efficiency analysis: The case of Taiwanese commercial banks. Eur. J. Oper. Res. 2016, 255, 411-423. [CrossRef]

40. Liu, S.T. A fuzzy DEA/AR approach to the selection of flexible manufacturing systems. Comput. Ind. Eng. 2008, 54, 66-76. [CrossRef]

41. Liu, S.T. Restricting weight flexibility in fuzzy two-stage DEA. Comput. Ind. Eng. 2014, 74, 149-160. [CrossRef]

42. Thompson, R.G.; Singleton, F.D.; Thrall, R.M.; Smith, B.A. Comparative site evaluation for locating a high-energy physics lab in Texas. Interface 1986, 16, 35-49. [CrossRef]

43. Global Energy Policy Research. Available online: http://www.gepr.org/ja/contents/20170214-01/ (accessed on 1 January 2020).

44. President. Available online: https://president.jp/articles/-/26265 (accessed on 1 January 2020). 